\title{
Scientific evidence for health effects attributed to the consumption of probiotics and prebiotics: an update for current perspectives and future challenges
}

\author{
Rafael Chacon Ruiz Martinez ${ }^{1}$, Raquel Bedani ${ }^{2}$ and Susana Marta Isay Saad ${ }^{2 *}$ \\ ${ }^{1}$ Department of Food and Experimental Nutrition, School of Pharmaceutical Sciences, University of São Paulo, Av. Prof. Lineu \\ Prestes, 580, CEP 05508-000, São Paulo, Brazil \\ ${ }^{2}$ Department of Biochemical and Pharmaceutical Technology, School of Pharmaceutical Sciences, University of São Paulo, \\ Av. Prof. Lineu Prestes, 580, CEP 05508-000, São Paulo, Brazil
}

(Submitted 14 May 2015 - Final revision received 20 August 2015 - Accepted 2 September 2015 - First published online 7 October 2015)

\begin{abstract}
Probiotics and prebiotics, mainly commercialised as food ingredients and also as supplements, are considered highly profitable niche markets. However, in recent years, the food industry has suffered from a series of health claim restrictions on probiotics and prebiotics in many parts of the world, including those made by the European Food Safety Authority. Therefore, we reviewed the core benefits of probiotic and prebiotic consumption on health. A number of studies have examined the prevention and/or management of intestinal infections, respiratory tract infections, CVD, osteoporosis, urogenital infections, cavities, periodontal disease and halitosis, allergic reactions, inflammatory bowel disease and irritable bowel syndrome and Helicobacter pylori gastric infections. In fact, a deeper understanding of the mechanisms involved in human microbiota and immune system modulation by probiotics and prebiotics relies on continuous efforts to establish suitable biomarkers of health and diseases risk factors for the design of clinical trials required for health claim approval. In spite of the promising results, the performance of large, long-term, well-planned, well-aligned clinical studies is crucial to provide more reliability and a more solid basis for the outcomes achieved and to support the potential use of probiotics and prebiotics in clinical practice.
\end{abstract}

Key words: Probiotics: Prebiotics: Inulin: Lactobacillus: Bifidobacterium: Health effects

The growing concern with food habits and their relation to health and longevity has stimulated the development of a large number of studies in the field of food science and nutrition. There has been considerable discussion on the role of the intestinal microbiota in the aetiology of a number of diseases and the effect of diet components on the modulation of the intestinal microbiota and its association with the reduced risk for illness development. As a result, in recent years, the concept of functional foods has been examining food additives that may exert beneficial effects on the composition and/or activity of the host intestinal microbiota, and an important class of functional foods has received considerable attention: probiotics and prebiotics.

Intestinal microbiota, a term used to replace the former name of intestinal microflora, is an ecosystem consisting of different ecological niches composed of a huge diversity of bacterial species and strains ${ }^{(1,2)}$. This microbial population increases throughout the gastrointestinal tract (GIT) showing approximately $10^{3}$ micro-organisms/ml of the luminal content in the duodenum, $10^{8}$ micro-organisms/g of the ileal content and up to $10^{12}$ micro-organisms/g of the colonic content ${ }^{(3,4)}$.

The wide diversity of intestinal microbiota has only recently been recognised because of the development and use of culture-independent molecular methods, which are based on the analysis of the $16 \mathrm{~S}$ ribosomal RNA. These techniques have indicated that most bacteria in intestinal microbiota from healthy individuals belong to three main phyla: Firmicutes, Bacteroidetes and Actinobacteria ${ }^{(5,6)}$. Each person presents a distinct and highly variable intestinal microbiota, at least at the species level; however, a stable core of intestinal colonists (intestinal microbiota-core) and of genes (microbiome-core) are shared by individuals and may be related to the intestinal function $^{(7-11)}$.

The intestinal microbiota is in direct contact with the intestinal mucosa. Both, along with the mucus, form the so-called mucosal barrier, an important defence system against

Abbreviations: CD, Crohn's disease; CDAD, Clostridium difficile-associated diarrhoea; CFU, colony-forming units; FOS, fructo-oligosaccharides; GIT, gastrointestinal tract; GOS, galacto-oligosaccharides; IBD, inflammatory bowel diseases; IBS, irritable bowel syndrome; LAB, lactic acid bacteria; RS, resistant starch; UC, ulcerative colitis.

* Corresponding author: S. M. I. Saad, fax +55 113815 6386, email susaad@usp.br 
potentially pathogenic and immunogenic factors present in the lumen. In fact, the mucous membrane separates the lumen containing the microbiota, organic food waste and secretions (salivary, gastric, biliary, pancreatic and intestinal) from the lymphoid tissue associated with the intestines ${ }^{(2)}$. The cells that make up the immune system are mainly concentrated in the lymphatic organs located in the lamina propria of the GIT. The lymphoid tissue associated with the intestine is composed of several follicular structures, Peyer's patches, T lymphocyte aggregates, antigen-presenting cells and B lymphocytes ${ }^{(2)}$.

The high metabolic activity of the intestinal microbiota, besides its nutritional role, results in a significant impact on the individual's health and well-being ${ }^{(10)}$. The interaction between the intestinal microbiota and the host generates several advantages for both. The main functions of the intestinal microbiota include participation in the intestinal wall formation; colonisation resistance against pathogens; production of SCFA; butyrate, propionate and acetate; production of vitamins, especially vitamin $\mathrm{B}$ and vitamin $\mathrm{K}$ complex; interactions with the mucosal immune system; and degradation of xenobiotics ${ }^{(9,12-16)}$.

According to Round \& Mazmanian ${ }^{(17)}$, a healthy GIT microbiota contains a balanced composition of several classes of bacteria, including the symbionts known as health-promoting micro-organisms such as Bifidobacterium spp. and Lactobacillus spp., the commensals, micro-organisms that allegedly provide neither benefits nor harm to the host, and pathobionts, potentially pathogenic micro-organisms.

Fluctuations in the composition of the intestinal ecosystem have been associated with various diseases, including imunnoinflammatory disorders, obesity and cancer ${ }^{(18-21)}$. The composition and metabolic activity of the intestinal microbiota can be modified by various factors, including antibiotic treatment, inflammatory processes, ageing, diet changes, GIT motility, host secretions, among others ${ }^{(1,22)}$. Changes in the diet, including the amount, type and balance of the main dietary macronutrients (carbohydrates, proteins and fats), may significantly affect the intestinal microbiota diversity, which may influence its functional relation with the host ${ }^{(23-25)}$.

Thus, there is a growing interest in alternatives that can beneficially modulate the intestinal microbiota, improving the individual's health and consequently reducing the risk for the development of diseases. The consumption of probiotic microorganisms and prebiotic ingredients is a promising alternative to beneficially influence the intestinal microbial ecology, maintaining the intestinal homoeostasis and controlling the dysbiosis, and, consequently, improving health ${ }^{(26,27)}$. Therefore, intestinal microbiota is an important target for interventions with probiotics and prebiotics, administered as supplements or food ingredients, with the specific goal of modulating the microbial community composition, as well as the microbiome functional capacity ${ }^{(28,29)}$. In this review paper, the key health benefits attributed to probiotic microorganisms and prebiotic fibre consumption will be discussed.

\section{Probiotics}

Several definitions of probiotics have been proposed over the years. However, a consensus statement on the scope and appropriate use of the term probiotic was recently given by the International Scientific Association for Probiotics and Prebiotics ${ }^{(30)}$ : probiotics are defined as live micro-organisms that, when administered in adequate amounts, confer a health benefit on the host'.

The vast majority of potentially probiotic lactic acid bacteria (LAB) belongs to the phylum Firmicutes, a very diverse group of bacteria with low $\mathrm{G}+\mathrm{C}$ genomic contents and which includes the Aerococcus, Enterococcus, Lactobacillus, Lactococcus, Leuconostoc, Oenococcus, Pediococcus, Streptococcus, Carnobacterium, Tetragenococcus, Vagococcus and Weissella genera ${ }^{(31)}$. The Bifidobacterium genus is considered by many scientists to be a member of the LAB group, as it shares some typical characteristics of this group, such as the production of lactic acid. However, this genus belongs to the phylum Actinobacteria, a group of bacteria with high $\mathrm{G}+\mathrm{C}$ genomic content and a distinct carbohydrate fermentation system when compared with the LAB belonging to the phylum Firmicutes ${ }^{(31)}$. Although Bifidobacterium and Lactobacillus genera do not belong to the same taxonomic group, in this review paper, merely for didactic purposes, the genus Bifidobacterium will be included when the LAB group is mentioned in the text.

For a micro-organism to be considered as a probiotic, certain criteria must be fulfilled, including the following: (1) even though certain commercially available probiotic strains are not of human origin, it is believed that if a probiotic is isolated from the GIT of human beings it is safe for human consumption and can be more effective within the intestinal ecosystem; (2) probiotic cultures should be recognised as safe (GRAS status - generally recognised as safe) for human consumption through scientific evidence or experiments based on the history of consumption by a significant number of subjects: bacteria of the genera Bifidobacterium spp. and Lactobacillus spp. have a long history of safe consumption without any reported harmful health effects; (3) the preparation of large-scale probiotics should be feasible, and it is very important that these micro-organisms are viable and active in the vehicles in which they are incorporated; (4) probiotics should be resistant to gastric and intestinal juices, as low $\mathrm{pH}$ is one of the host defence mechanisms against ingested micro-organisms, including probiotics; (5) probiotics should adhere to human intestinal cells and intestinal mucins, which improve their persistence and allow their growth in the intestine, and may favour the competitive exclusion of potential pathogens of the mucosal surface; (6) probiotics should produce antimicrobial substances against intestinal pathogens in order to restore the healthy microbiota composition; (7) probiotics must be safe when ingested through food consumption and during clinical use, even for immunocompromised individuals; (8) probiotics must have their safety and efficacy established through randomised and placebo-controlled clinical trials ${ }^{(32,33)}$.

The sufficient dose of probiotic micro-organisms to lead to beneficial health effects may vary depending on the strain and the product. In general, products containing probiotic micro-organisms should have a minimum number of viable cells, with proven efficacy established based on human clinical trials, estimated to be between $10^{6}$ and $10^{8}$ colony-forming units 
per gram (CFU/g) of end product or $10^{8}-10^{10} \mathrm{CFU} / \mathrm{d}$ (considering $100 \mathrm{~g}$ or $100 \mathrm{ml}$ of the ingested food) ${ }^{(34)}$. Brazilian legislation recommends a minimum probiotic population ranging from $10^{8}$ up to $10^{9} \mathrm{CFU} /$ daily serving portion of the food product to obtain a beneficial health effect in the gut ${ }^{(35)}$. A similar number of viable probiotic cells $\left(10^{9} \mathrm{CFU}\right)$ per serving portion, consumed on a daily basis, is also recommended by Health Canada ${ }^{(36)}$ and the Italian Health Ministry ${ }^{(37)}$.

The ideal amount of probiotic micro-organisms to be administered is not easy to be determined. It is believed that it is strain specific and depends on the type of the intended beneficial effect, and thus different effects may require different strains and different probiotic quantities. Of course, the total probiotic microbial population may not be low if the goal is to influence the composition and/or the metabolic activity of the host microbiota ${ }^{(2)}$. Other factors may be involved in determining the daily probiotic dose, including the daily administration frequency (one to four times); the administration period (before, during or after meals); the duration of administration (from $1 \mathrm{~d}$ to several months); the vehicle used for the probiotic delivery (fermented food, drink, capsule, tablet or powder); and the viability of the probiotic $\operatorname{strain}^{(38)}$.

\section{Prebiotics}

Prebiotics are defined as 'selectively fermentable ingredients that allow specific changes in the composition and/or activity of gastrointestinal microbiota that allow benefits to the host ${ }^{\text {(39,40). }}$

On the basis of this definition, the requirements that a dietary ingredient must meet in order to be characterised as a prebiotic include the following. (1) The fermentability should be demonstrated in in vitro tests that simulate, for example, physiological conditions found in the GIT. Promising substrates should be evaluated in randomised and placebo-controlled clinical studies, in order to confirm the positive outcomes obtained by in vitro studies. (2) The main trait of a prebiotic is to be a selective substrate for one or more beneficial GIT commensal bacteria, which are stimulated to multiply and/or are metabolically activated, beneficially altering the colonic microbiota composition of the host. To confirm the selectivity of a prebiotic, it is of great importance to monitor the changes in the faecal microbiota during supplementation studies with the prebiotic through in vitro and in vivo tests. Although both criteria are essential, selectivity is the most important, as well as the most difficult, to be achieved ${ }^{(32,39)}$. Moreover, selectivity consists of a key attribute that distinguishes prebiotics from other dietary fibres ${ }^{(41)}$.

Although nondigestibility has been excluded from the latest definition of prebiotics, these fibres should not be digestible by human enzymes or be only partially digestible in order to reach, in adequate amounts, more distant segments of the $\mathrm{GIT}^{(33)}$. Nowadays, the main well-known prebiotics are non-digestible carbohydrates including fructo-oligosaccharides (FOS), inulin, galacto-oligosaccharides (GOS), trans-galacto-oligosaccharides (TOS) and lactulose. Other non-digestible carbohydrates have been studied for their prebiotic potential including soya bean oligosaccharides, isomalto-oligosaccharides, xylo-oligosaccharides, polydextrose, glucans, cereal-derived arabinoxylans and arabinoxylan oligosaccharides $^{(40,42,43)}$. However, most of the data available in the scientific literature on prebiotic effects are related to inulin and FOS.

Several studies have evaluated the potential of resistant starch (RS), a high-amylose starch, to act as a prebiotic ingredient ${ }^{(40)}$. A study developed by Crittenden et al. ${ }^{(44)}$ reported that various Bifidobacterium strains, including B. adolescentis, B. bifidum, $B$. breve, B. infantis, B. lactis and B. longum, were able to hydrolyse RS. Although the evidence of RS as a prebiotic compound is somewhat limited, as most studies have been performed using animal models, many of the beneficial effects in the large bowel appear to be caused by SCFA formed by bacterial fermentation ${ }^{(45,46)}$. According to available data, human colonic bacteria may ferment RS to SCFA, mainly acetate, propionate and butyrate ${ }^{(47)}$. Nevertheless, further research regarding the potential of RS as a prebiotic compound in human is still necessary, especially regarding the ability to selectively stimulate beneficial micro-organisms.

Prebiotics are available and may be extracted from plant sources. However, most of the prebiotic fibres used as food ingredients are synthesised commercially through enzymatic or chemical methods ${ }^{(48)}$.

As in the case of probiotics, in order to ensure a continuous effect, prebiotics should be consumed daily. Favourable changes in the intestinal microbiota were observed at doses of $4-20 \mathrm{~g} / \mathrm{d}$ of inulin and/or FOS ${ }^{(40,41)}$. The daily dose of prebiotics (inulin, FOS and lactulose) per serving portion of the food product recommended by the Brazilian legislation is of $3 \mathrm{~g}$ for solid foods and of $1.5 \mathrm{~g}$ for liquid foods ${ }^{(35)}$.

The molecular structure of prebiotics is important to determine the physiological effects and also which species of microorganisms will be able to use them as $\mathrm{C}$ and energy sources in the intestine. However, despite the diversity of molecular weights, compositions of sugars and structural connections within the range of prebiotic ingredients, bifidobacteria are the micro-organisms mostly involved in this response. The mechanisms by which prebiotics promote specific growth of bifidobacteria in the intestinal microbiota are still not clear. However, several hypotheses ought to be mentioned, including the following: (1) bifidobacteria may use a wide variety of oligosaccharides and complex carbohydrates as $\mathrm{C}$ and energy sources; (2) in the presence of several non-digestible oligosaccharides, bifidobacteria have higher growth rates, when compared with putrefactive or potentially pathogenic bacteria in the intestine environment; (3) although other genera of bacteria (Lactobacillus, Bacteroides and Eubacteria) are able to multiply in vitro using prebiotic sources, bifidobacteria seem to do it in a more efficient way. Furthermore, bifidobacteria are tolerant to SCFA and to the acidification of the intestinal environment. Bifidobacteria produce permeases that are able to internalise non-digestible oligosaccharides, which are then metabolised, thus minimising the release of simple sugars that could be consumed by other intestinal bacteria ${ }^{(48)}$.

\section{Synbiotics}

A synbiotic product combines one or more probiotic microorganism with a prebiotic fibre. These food ingredients together 
in a product may lead to the previous adaptation of the probiotic to the prebiotic substrate, which might promote a positive interaction between the probiotic and the prebiotic in vivo. In some cases, this may lead to a competitive advantage for the probiotic, if consumed along with the prebiotic fibre. Alternatively, this synbiotic effect can be directed to different 'target' regions of the small and large intestines. The consumption of appropriately selected probiotics and prebiotics may increase the beneficial effects of both synergistically, as the stimulus of known probiotic strains leads to the choice of the most profitable combination between substrate and micro-organism $^{(49-52)}$.

Both approaches may directly or indirectly be in accordance with the definition of synbiotics. However, according to Kolida \& Gibson ${ }^{(33)}$, the synergistic approach tends to be the most important.

The synbiotic concept offers great potential to increase the effectiveness of this class of functional foods, as it explores the advantages that a combination of prebiotics and probiotics may offer, not only to health but also to the stability of the product, during its storage period ${ }^{(33,53)}$.

\section{Health effects associated with probiotic and prebiotic consumption}

\section{Intestinal infections}

Most of the studies on the clinical use of probiotics are focused on the GIT. In this site, it is believed that probiotics are able to compete with pathogenic micro-organisms for adhesion sites and nutrients. Besides, they may produce different antimicrobial compounds, a process called 'colonisation resistance' or 'competitive exclusion' ${ }^{, 54,55)}$. In terms of prebiotics, their main characteristics are resistance to digestive enzymes in the human gut, fermentability by the colonic microbiota and bifidogenic and $\mathrm{pH}$-lowering effects. Accordingly, because of the last characteristic, prebiotics could inhibit certain strains of potentially pathogenic bacteria, particularly Clostridium, and prevent diarrhoea ${ }^{(56)}$.

Intestinal infections are characterised by an imbalance of the normal intestinal microbiota, which leads to increased pathogenic micro-organism populations. To determine the efficacy of probiotic strains in the treatment of these infections, a number of clinical studies have been performed ${ }^{(57)}$. Some studies showed that different probiotic strains administered in children at the beginning of the diarrhoea episode were able to reduce the infection duration and/or intensity ${ }^{(58,59)}$. In Europe, the use of probiotics for acute infectious diarrhoea in children is an accepted therapy ${ }^{(60)}$. Table 1 shows some of the publications cited in this review, which demonstrated beneficial effects of the consumption of probiotics and/or prebiotics against intestinal infections and other pathological conditions.

The results reported for probiotic effects against antibioticassociated diarrhoea are rather heterogeneous and sometimes even contradictory. Studies conducted by Arvola et al. ${ }^{(61)}$ and Vanderhoof et al. ${ }^{(62)}$ demonstrated that Lactobacillus GG was effective in reducing the adverse effects and diarrhoea commonly associated with the use of antibiotics.
However, according to Marchand \& Vandenplas ${ }^{(63)}$, several papers reported that some probiotic micro-organisms did not present any clinical efficacy in the treatment of this condition. A systematic review of probiotic effectiveness also indicated that findings reported in the scientific literature do not support the use of probiotics for Clostridium difficile infection ${ }^{(64)}$. In contrast to probiotics, there are few clinical trials on prebiotic effects in preventing antibiotic-associated diarrhoea ${ }^{(65)}$.

According to Marchand \& Vandenplas ${ }^{(63)}$, at least three clinical studies have demonstrated the potential of the yeast Saccharomyces boulardii in reducing antibiotic-associated diarrhoea. Thompson ${ }^{(66)}$ also reported the beneficial effects of $S$. boulardii on Clostridium difficile-associated diarrhoea (CDAD). Moreover, according to a meta-analysis, probiotic lactobacilli may effectively prevent antibiotic-associated diarrhoea both in children and in elderly people ${ }^{(67)}$. In the same way, Hickson et al. ${ }^{(68)}$ observed that a probiotic drink containing Lactobacillus casei DN-114 001, Lactobacillus bulgaricus and Streptococcus thermophilus lowered the risk for developing antibiotic and CDAD among seniors in 22 and $17 \%$ cases, respectively. On the other hand, according to a study conducted by Pozzoni et al. ${ }^{(69)}$, in which 564 hospitalised patients were followed up for 3 months, the probiotic microorganism did not prevent antibiotic-associated diarrhoea caused by $C$. difficile.

Although studies provide evidence that selected probiotics may significantly decrease the risk of diarrhoea in subjects treated with antibiotics, not all antimicrobial agents are equal in causing antibiotic-associated diarrhoea. Therefore, conclusions on the efficacy of probiotics in preventing diarrhoea caused by any particular antibiotic class may not be made ${ }^{(60)}$.

A review published by Floch et al. ${ }^{(58)}$ indicated that probiotics are helpful in the prevention of CDAD in both adults and children, especially when Lactobacillus rbamnosus GG and $S$. boulardii are combined. Several placebo-controlled studies have suggested that Lactobacillus GG could be used to treat several forms of diarrhoea, including rotavirus diarrhoea, travellers' diarrhoea and relapsing $C$. difficile diarrhoea ${ }^{(70,71)}$. On the other hand, according to Graul et al. ${ }^{(72)}$, two trials using L. rhamnosus GG for the prevention of CDAD failed to demonstrate that this supplement could reduce the incidence of this disease ${ }^{(61,73)}$.

In this scenario, although probiotics may be effective in the prevention of infection caused by $C$. difficile, so far there is no sufficient scientific evidence to unambiguously prove the effectiveness of this approach ${ }^{(58,74)}$. However, it is important to stress out that the reduction of $\mathrm{CDAD}$ risk by reducing the presence of the pathogen toxin is indeed considered a beneficial physiological effect. In reality, the European Food Safety Authority (EFSA) ${ }^{(75)}$ concluded that there is insufficient evidence to establish a cause and effect relationship between the consumption of Actimel $^{\circledR}$ (a fermented milk containing L. casei DN-114 001 plus yogurt bacteria; Danone) and the reduction of risk for developing C. difficile diarrhoea in patients receiving antibiotics by reducing the presence of $C$. difficile toxins. On the other hand, a randomised and controlled study conducted by Lewis et al. ${ }^{(76)}$ demonstrated that the consumption of the prebiotic oligofructose (with a daily ingestion of $12 \mathrm{~g}$ ) presented a positive effect in the treatment of CDAD. 
Table 1. Beneficial effects of probiotics and/or prebiotics on important human pathologic conditions

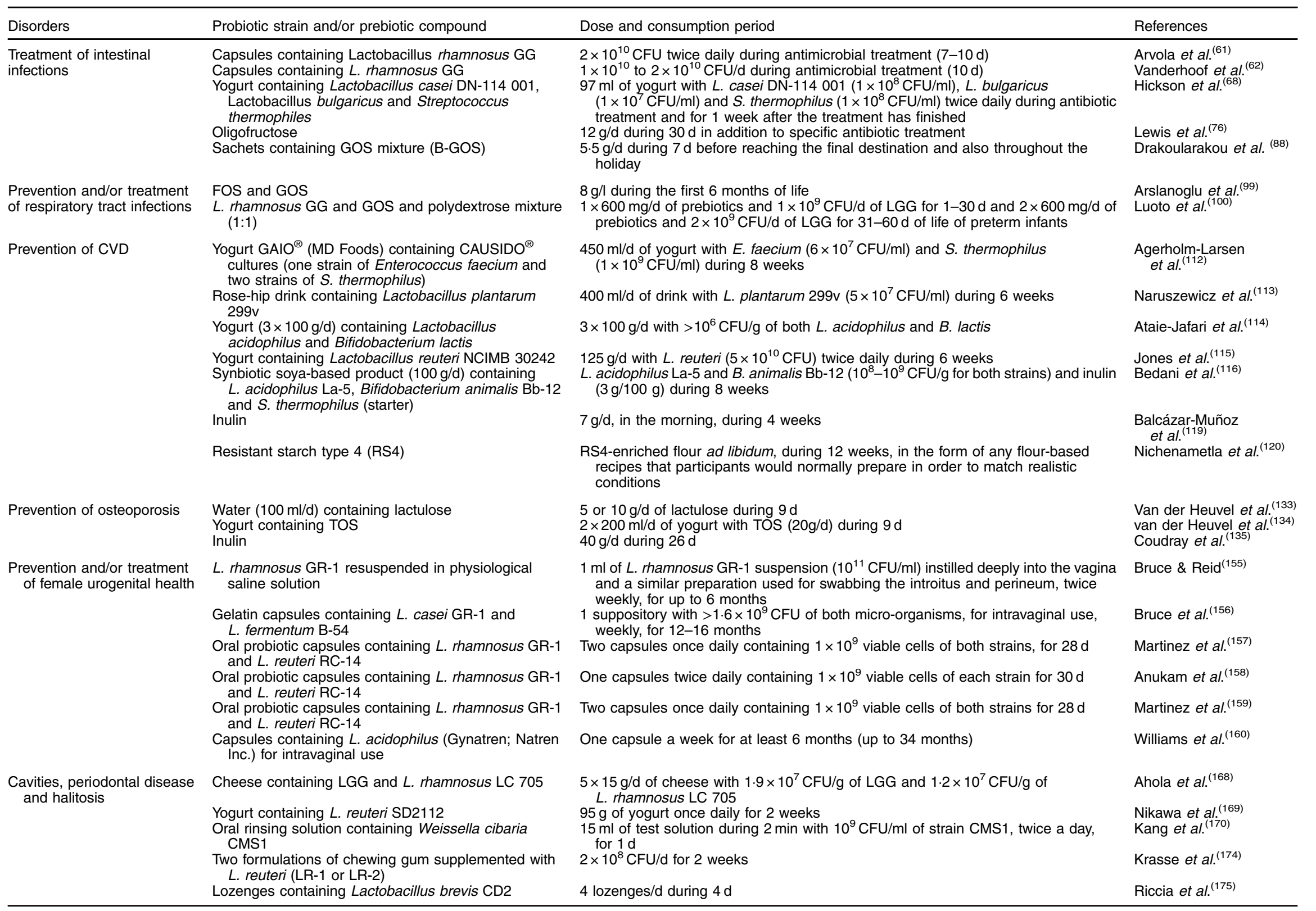




\section{NS British Journal of Nutrition}

Table 1 Continued

\begin{tabular}{|c|c|}
\hline Disorders & Probiotic strain and/or prebiotic compound \\
\hline $\begin{array}{l}\text { Prevention and/or treatment } \\
\text { of allergic reactions }\end{array}$ & $\begin{array}{l}\text { Capsule containing L. rhamnosus GG, L. rhamnosus } \\
\text { LC705, Bifidobacterium breve Bb99 and } \\
\text { Propionibacterium freudenreichii ssp. shermanii JS } \\
\text { and sugar syrup containing GOS } \\
\text { Capsule containing } L \text {. rhamnosus GG, } L \text {. rhamnosus } \\
\text { LC705, B. breve Bb99 and } P \text {. freudenreichii ssp. } \\
\text { shermanii JS and sugar syrup containing GOS } \\
\text { L. rhamnosus GG }\end{array}$ \\
\hline & $\begin{array}{l}\text { Dairy fermented product with Lactobacillus grasseri } \\
\text { CECT5714 and Lactobacillus coryniformis } \\
\text { CECT5711 } \\
\text { Hydrolysed whey formula fortified with L. GG (ATCC } \\
53103 \text { ); restricted diet and supplementation with } \\
\text { LGG } \\
\text { scGOS and IcFOS }\end{array}$ \\
\hline
\end{tabular}

Treatment of inflammatory bowel disease and irritable bowel disease

Treatment of Helicobacter pylori gastric infections

scGOS and IcFOS

Sachet containing lyophilised probiotic culture VSL\#3 Malted milk drink containing Bifidobacterium infantis 35624

Capsule containing B. infantis 35624

Drink containing $3.5 \mathrm{~g}$ or $7.0 \mathrm{~g}$ of prebiotic (TOS mixture)

Tablet (Flortec; Anidral Co.) containing both lyophil Lactobacillus paracasei B21060 and prebiotics (XOS $(700 \mathrm{mg})$, glutamine $(500 \mathrm{mg})$ and

arabinogalactone $(1243 \mathrm{mg})$ ) or prebiotics only

Whey-based culture supernatant of Lactobacillus johnsonii La1
Dose and consumption period

References

1 capsule with $5 \times 10^{9} \mathrm{CFU}$ of LGG, $5 \times 10^{9} \mathrm{CFU}$ of LC705, $2 \times 10^{8} \mathrm{CFU}$ of Bb99 and Kukkonen et al. ${ }^{(186}$ $2 \times 10^{9} \mathrm{CFU}$ of $\mathrm{JS}$ twice daily for 1 month before delivery to mothers and

1 capsule $+0.8 \mathrm{~g}$ of GOS a day for 6 months to infants

2 capsules with $5 \times 10^{9} \mathrm{CFU}$ of LGG, $5 \times 10^{9} \mathrm{CFU}$ of LC705, $2 \times 10^{8} \mathrm{CFU}$ of Bb99 and Marschan et al. ${ }^{(187)}$ $2 \times 10^{9} \mathrm{CFU}$ of JS (in a capsule), once a day for 1 month before delivery to mothers

$2 \times 10^{10} / \mathrm{d}$ to mothers for 4 weeks before giving birth and during breast-feeding (until Rautava et al. ${ }^{(188)}$ the child was 3 months old)

$00 \mathrm{ml}$ of a dairy product containing at least $10^{6} \mathrm{CFU} / \mathrm{g}$ of each strain once a day for Martinez-Canavate

et al ${ }^{(19)}$

LC-1 fermented milk containing L. johnsonii La1

Fermented milk containing $L$. johnsonii 1 (La1)

Yogurt containing $L$. acidophilus La-5, B. animalis $\mathrm{Bb}-12, \mathrm{~L}$. bulgaricus and $S$. thermophiles

Pill containing L reuteri ATCC 55730

Chewable tablet containing L. reuteri DSM 17938 and L. reuteri ATCC PTA 6475
$500 \mathrm{ml}$ or $1000 \mathrm{ml}$ of the formula containing $5 \times 10^{8} \mathrm{CFU} / \mathrm{g}$ of LGG, depending on the age of the infant, for 1 month; $2 \times 10^{10} \mathrm{CFU}$ of LGG given twice daily for 1 month to the nursing mothers of atopic infants

xtensively hydrolysed cow's milk whey protein supplemented with $0.8 \mathrm{~g}$ of scGOS/ IcFOS $/ 100 \mathrm{ml}$ for 6 months

$3.6 \times 10^{12} \mathrm{CFU}$ twice daily for 8 weeks

$1 \times 10^{10} \mathrm{CFU}$ once a day for 8 weeks

$1 \times 10^{8} \mathrm{CFU}$ once daily for 4 weeks

Daily ingestion of the drink, before breakfast (during both periods: the first treatment and after 2-week washout)

$5 \times 10^{9}$ CFU twice daily for 12 weeks

Majamaa \& Isolauri ${ }^{(192)}$

Schouten et al. ${ }^{(204)}$

$\mathrm{Ng}$ et al. ${ }^{(217)}$

O'Mahony et al. ${ }^{(230)}$

Whorwell et al. ${ }^{(23)}$

Silk et al. ${ }^{(235)}$

Andriulli et al. ${ }^{(236)}$

$50 \mathrm{ml}$ of La1 supernatant, four times a day, during $14 \mathrm{~d}$

Michetti et al. ${ }^{(240)}$

$180 \mathrm{ml}$ of the fermented milk containing $10^{7} \mathrm{CFU} / \mathrm{ml}$ daily for 3 weeks; during the last 2 weeks, volunteers also received clarithromycin $(500 \mathrm{mg})$ $125 \mathrm{~g}$ of fermented milk with $10^{6}-10^{7} \mathrm{CFU} / \mathrm{g}$ of Lj1 twice daily, during the first 3 weeks and once a day for the next 13 weeks

$230 \mathrm{ml}$ of yogurt with $10^{7} \mathrm{CFU} / \mathrm{ml}$ of both La-5 and Bb-12 twice a day for 6 weeks

One pill a day containing $10^{8} \mathrm{CFU}$, for $20 \mathrm{~d}$ (before, subjects had received omeprazole and amoxicillin for $5 \mathrm{~d}$, followed by omeprazole, clarithromycin and tinidazole for the next $5 \mathrm{~d}$ )

tinidazole for the next 5 d) $1 \times 10^{8} \mathrm{CFU} / \mathrm{strain}$, daily, duning $90 \mathrm{~d}$; during the eradication treatment (days 29-35), patients also received clarithromycin and amoxicillin
Felley et al. ${ }^{(242)}$

Pantoflickova et al. ${ }^{(243)}$

Wang et al. ${ }^{(244)}$

Lionetti et al. (245)

Francavilla et al. ${ }^{(246)}$

FOS, fructo-oligosaccharides; GOS: galacto-oligosaccharides; TOS, trans-galacto-oliogosaccharides; scGOS, short-chain galacto-oligosaccharides; IcFOS, Iong-chain fructo-oligosaccharides; XOS, xylo-oligosaccharides; VSL\#3: L. casei, L. plantarum, L. acidophilus, L. delbrueckii spp. bulgaricus, B. longum, B. breve, B. infantis and S. thermophilus. 
Rotavirus is the leading cause of severe diarrhoea in children worldwide $^{(77)}$. The organism invades the epithelial cells of the small intestine and multiplies, leading to the destruction of the intestinal mucosa and an increased intestinal permeability ${ }^{(78)}$. Several studies have shown that the probiotic strains L. rhamnosus GG, Lactobacillus reuteri, L. casei Shirota and Bifidobacterium animalis spp. lactis $\mathrm{Bb}-12$ were able to reduce the duration of rotavirus diarrhoea in about $1 \mathrm{~d}^{(79-82)}$. The effectiveness of certain probiotic strains in the treatment/ prevention of infection is closely related to both strain and dose of the micro-organism used ${ }^{(57,72,83)}$.

Probiotics may also be helpful in the prevention of travellers' diarrhoea, a condition commonly observed in people travelling to countries with lower economic and social development and warmer climates ${ }^{(71)}$. Hilton et al. ${ }^{(84)}$ showed that Lactobacillus GG was able to prevent this infection. However, Oksanen et $a l .{ }^{(85)}$ reported limited effect with the use of the same strain. In general, the clinical evidence for travellers' diarrhoea prevention using probiotic micro-organisms is still limited ${ }^{(86)}$, in particular because of the reduced number of interventions and variability of the experimental protocols used ${ }^{(87)}$. The wide variety of the potential causes of traveller's diarrhoea and the difficulty of volunteers to follow study protocols during their trips bring additional challenges for the intervention with probiotics when targeting this type of illness ${ }^{(86)}$.

The role of prebiotics in the prevention of travellers' diarrhoea has also been investigated through randomised, double-blind, placebo-controlled studies, and results are also inconsistent. According to Drakoularakou et $a l^{(88)}$, a GOS mixture (B-GOS) showed significant potential to prevent the incidence and symptoms of travellers' diarrhoea in subjects who travelled for at least 2 weeks to a country of low or high risk for the condition. However, Cummings et al. ${ }^{(89)}$ demonstrated that the consumption of $10 \mathrm{~g}$ of FOS daily, before and during holiday to medium- and high-risk destinations for travellers' diarrhoea, was not effective in preventing it. Moreover, Virk et $a{ }^{(90)}$ observed that the use of an oral synbiotic product containing Enterococcus faecium SF68, Saccharomyces cerevisae CNCM I 4444 and FOS, although safe, was ineffective in preventing travellers' diarrhoea among people who visited areas with increased risk for the condition and did not decrease its duration or the need for antibiotics when it actually occurred.

Even though some studies have shown promising findings regarding prebiotic effects on intestinal microbiota, there is not enough evidence to recommend prebiotics for the prevention or treatment of diarrhoea. In general, it is important to highlight that there are many different causes of diarrhoea, and the studies using probiotic strains and prebiotic ingredients on the same type of diarrhoea may use different criteria in the selection of volunteers and various outcome parameters, which makes it difficult to draw conclusive remarks about the beneficial effects of these bioactive compounds on this pathology. It seems that probiotics are more effective in the prevention of rotavirus and antibiotic-associated diarrhoea than travellers' diarrhoea $^{(86)}$. Nevertheless, further studies about the impact of probiotics and prebiotics on the prevention and the management of diarrhoea are mandatory and could propel (or not) their use in medical settings.

\section{Respiratory tract infections}

Respiratory tract infections victimise a high proportion of individuals and are related to high morbidity and mortality rates ${ }^{(91)}$. This condition, common among children, is normally selflimiting, and the risk for the development of complications is considered small ${ }^{(92)}$. Antibiotics are commonly used in an inappropriate manner for the treatment of the pathology and may therefore select resistant micro-organisms, an increasing global phenomenon ${ }^{(93,94)}$.

Initially, several studies carried out with animal models evidenced a potentially protective effect of probiotics against bacterial and viral respiratory tract infections. This positive outcome was attributed to the immune system stimulation ${ }^{\text {(95-97) }}$.

Vouloumanou et $a l .{ }^{(91)}$ published a systematic review on fourteen randomised controlled trials that evaluated the ability of different probiotics (Lactobacillus and Bifidobacterium strains - alone and combined, and a non-pathogenic Enterococcus faecalis strain) for the prevention of respiratory tract infections. The authors concluded that the probiotic strains tested may possibly have a positive effect on the severity and extent of the symptoms, although they may not be useful in reducing the incidence of the illness. More recently, King et $a{ }^{(98)}$ published a systematic review that investigated the effect of probiotics, particularly Lactobacillus and Bifidobacterium strains, on acute respiratory infections in otherwise healthy children and adults. The authors included twenty-one randomised controlled trials - of which twelve were considered to have a low risk of bias - and observed that subjects who received probiotics had reduced number of days of disorder and less absenteeism (days away from day care/school/work), in comparison with patients in the placebo group.

Arslanoglu et $a l .{ }^{(99)}$ conducted a randomised, double-blind, placebo-controlled trial in which healthy infants consumed a prebiotic formula containing FOS and GOS or placebo (maltodextrin) during the first 6 months of life. The authors reported significantly fewer episodes of all types of infections combined, as well as a tendency to have fewer upper respiratory tract infection episodes in the probiotic group, in comparison with the placebo group. Arslanoglu et al. ${ }^{(99)}$ also pointed out that the cumulative incidence of any recurring respiratory infections was significantly lower in infants who received prebiotics, compared with infants fed placebo. Even though the authors did not clarify the specific mechanism(s) of action involved in the positive outcomes observed, they hypothesised that changes in the intestinal microbiota could have had an important role.

Luoto et $a l^{(100)}$ investigated the impact of prebiotic and probiotic supplementation for the prevention of rhinovirus infections in preterm infants. The researchers carried out a randomised, double-blind, placebo-controlled trial including ninety-four preterm infants, who received oral prebiotics (GOS and polydextrose mixture, 1:1), a probiotic (L. rhamnosus GG, ATCC 53103) or placebo (microcrystalline cellulose) from 3 up to $60 \mathrm{~d}$ of life. Follow-up visits were performed at the ages of 1 , 2, 4, 6 and 12 months, whereas an additional telephone call to the parents occurred at the age of 9 months. Throughout the study, the authors observed a significantly lower incidence of 
respiratory tract infections, including rhinovirus infections, in the prebiotic and probiotic groups, compared with infants fed placebo. However, these researchers also reported that neither the probiotic nor the prebiotic interventions had any influence on the duration and severity of the symptomatic rhinovirus infections.

In another study, Puccio et al. ${ }^{(101)}$ evaluated 187 infants who were not breast-fed after $14 \mathrm{~d}$ of life and randomly received an experimental formula containing the probiotic strain B. longum BL99 and a prebiotic mixture of FOS and GOS or a control formula. The authors observed equivalent mean weight gain in both groups, as well as no statistical difference in the incidence of respiratory tract infections.

Although certain published studies have shown encouraging results, there are still some important gaps in our knowledge of the impact of probiotics and/or prebiotics on respiratory tract infections. In general, the research in this field of application has shown heterogeneous findings regarding, for example, probiotic strains, types of prebiotic ingredients, doses, mode and period of administration. Another aspect that could be better explored includes the use of symbiotic formulations to enhance the potential beneficial effects on respiratory tract infections. Thus, more clinical trials are essential to undeniably attest the efficacy of probiotics and prebiotics in the prevention and/or treatment of respiratory tract infections, and more in vitro studies are required to elucidate the mechanisms of action involved.

\section{$C V D$}

CVD are the leading cause of death in the world, and their incidence has been increasing in recent years ${ }^{(102)}$. Among the different risk factors involved in their pathogenesis, hypercholesterolaemia is the main factor ${ }^{(103)}$. To reduce the incidence of CVD, it is necessary to decrease cholesterol levels in hypercholesterolaemic subjects, which may be achieved using both pharmacological and non-pharmacological interventions. Many patients prefer non-medicamental treatments for the reduction of the blood cholesterol rate because of the frequent adverse effects related to the use of lipid-lowering drugs, medicine contraindications or the personal preference for natural or alternative therapies ${ }^{(104)}$.

Mann \& Spoerry ${ }^{(105)}$ were the first researchers to observe the hypocholesterolaemic activity of fermented milk in a Maasai tribe, located in Kenya. Since then, many scientists have used animal and human models to evaluate the effects of probiotic micro-organisms on serum cholesterol level, and the probiotic benefits have been emphasised over the last 40 years.

Hepatic biosynthesis and the intestinal absorption are two sources of cholesterol in the human body, and both have an important role in the overall balance. On the basis of in vitro and in vivo studies, certain mechanisms have been proposed to explain the inhibition of cholesterol absorption in the small intestine, namely (i) linkage and incorporation of cholesterol by the bacterial cells; (ii) the suppression of bile acid reabsorption, mediated by the bile acid hydrolase of bacterial origin, which catalyses the deconjugation of bile acid salts, releasing free primary bile acids excreted in faeces in higher quantities; (iii) co-precipitation of cholesterol with deconjugated bile salts; (iv) conversion of cholesterol into coprostanol; and (v) production of SCFA by probiotics ${ }^{(106,107)}$.

More recently, studies have shown that several compounds implicated in cholesterol metabolism may be involved in the cholesterol-reducing ability of probiotic micro-organisms; however, this association is not fully understood ${ }^{(108)}$. These compounds include the protein NPC1L1 ${ }^{(109)}$, and the enzymes 3-hydroxy-3-methyl-glutaryl-CoA reductase ${ }^{(110)}$ and $7 \alpha, 27 \alpha$ hydrolase ${ }^{(111)}$.

Agerholm-Larsen et al. ${ }^{(112)}$ conducted a double-blind placebo-controlled study to evaluate the effect of a milk product $\left(\mathrm{GAIO}^{\circledR} ; \mathrm{MD}\right.$ Foods) containing the $\mathrm{CAUSIDO}^{\circledR}$ probiotic cultures (one strain of Enterococcus faecium and two strains of $S$. thermophilus) and two alternative products on the risk factors for the development of CVD in overweight and obese patients. The researchers observed that after 8 weeks of consuming the product the CAUSIDO $^{\circledR}$ cultures reduced LDL-cholesterol levels and increased fibrinogen rates in overweight patients. Although high levels of fibrinogen are considered a risk factor for the development of CVD, the authors observed that its levels remained within normal ranges (4.5-10 $3 \mu \mathrm{mol} / \mathrm{l})$. Naruszewicz et al. ${ }^{(113)}$ performed an interesting study that evaluated a group of smokers who ingested daily, for 6 weeks, a drink containing the probiotic Lactobacillus plantarum $299 \mathrm{v}$ strain. At the end of this period, the authors observed that the probiotic group showed a reduction in the systolic blood pressure and in the concentrations of leptin and fibrinogen, when compared with the control group. Ataie-Jafari et $a l^{(114)}$ evaluated a group of people with hypercholesterolaemia and reported that after 6 weeks of consumption of a yogurt containing Lactobacillus acidophilus and B. lactis the blood cholesterol rates were significantly lowered, compared with the group that consumed traditional yogurt. Moreover, Jones et $a$. $^{(115)}$ demonstrated that the consumption of a yogurt containing microencapsulated bile salt hydrolase-active $L$. reuteri NCIMB 30242, taken twice during a 6-week period, was effective and safe for the reduction of LDL-cholesterol, total cholesterol and non-HDL-cholesterol in hipercholesterolaemic adults.

Bedani et $a l^{(116)}$ evaluated the effect of a synbiotic soya-based product supplemented with okara soya bean by-product on the risk factors for CVD. The authors conducted a randomised, double-blind placebo-controlled trial, in which thirty-six normocholesterolaemic men were assigned into two groups: eighteen subjects consumed, on a daily basis, $100 \mathrm{~g}$ of the synbiotic food product fermented with $L$. acidophilus La-5, B. animalis Bb-12 and $S$. thermophilus (starter culture), whereas eighteen subjects consumed daily $100 \mathrm{~g}$ of unfermented soya-based product (placebo group), both for 8 weeks. Fasting blood samples and anthropometric measurements were obtained at the baseline $\left(\mathrm{T}_{0}\right)$ and after $4\left(\mathrm{~T}_{4}\right)$ and $8\left(\mathrm{~T}_{8}\right)$ weeks of the food product consumption. The authors observed a significant reduction in LDL-cholesterol mean values and a significant improvement of the LDL-cholesterol:HDL-cholesterol ratio in the synbiotic group. Furthermore, a trend for a LDL-cholesterol and LDL-cholesterol:HDL-cholesterol ratio reduction (obtained as the mean differences between $\mathrm{T}_{8}$ and $\mathrm{T}_{0}$ ) was higher in the synbiotic group, when compared with the placebo group. 
On the other hand, some studies did not find any significant effects regarding serum cholesterol reduction with the consumption of probiotic cultures ${ }^{(117,118)}$.

Some researchers have investigated the effects of prebiotics on cholesterol levels, but the results were not homogeneous. Balcázar-Muñoz et al. ${ }^{(119)}$ reported that the consumption of inulin ( $7 \mathrm{~g} / \mathrm{d})$ during 4 weeks by obese and hypercholesterolaemic subjects led to a significant reduction in total cholesterol, LDL-cholesterol, VLDL-cholesterol and TAG levels, when compared with subjects who received placebo. An interesting study published by Nichenametla et $a l^{(120)}$ evaluated individuals diagnosed with or without the metabolic syndrome (MetS) according to the International Diabetes Federation criteria - who were enrolled in a double-blind, placebo-controlled, cluster crossover intervention. The authors studied the effects of exchanging enriched flour (containing RS type 4) for regular/ control flour in different comorbidities associated with the MetS. The authors observed that the prebiotic consumption improved dyslipidaemia and body composition. On the other hand, Giacco et $a l .{ }^{(121)}$ reported that the daily intake of $10.6 \mathrm{~g}$ of short-chain FOS for 2 months by mild hypercholesterolaemic individuals had no major effects on lipid metabolism, when compared with consumption of placebo. However, Kellow et al. ${ }^{(122)}$ emphasised that the conclusions of these studies were limited, as they evaluated relatively short-term prebiotic interventions periods, and longer periods would be required to draw stronger conclusions.

Other valuable studies on the role of prebiotics regarding the prevention of CVD using animal models have also been published. Rault-Nania et $a l^{(123)}$ demonstrated, through studies conducted with mice, that the addition of long-chain inulins in the animals' diet was able to reduce the formation of atherosclerotic plaques. Ranganna et al. ${ }^{(124)}$ reported that the SCFA obtained from the fermentation of dietary fibres may modulate the expression of multiple genes involved in the atherosclerosis process.

Although several studies support the hypothesis that probiotics and/or prebiotics may reduce the risk of CVD, other researchers reported controversial findings. The discrepancies found among studies could be explained by the lack of dose-response studies in order to determine the 'minimum effective dose' required to promote, for example, an improvement of the lipid profile in humans $^{(106)}$. In addition, although several mechanisms of probiotic and prebiotic actions have been proposed, most of them are based on in vitro tests. In this sense, new in vivo studies are needed so that these mechanisms can be properly clarified.

In recent years, evidence has pointed to the possible relationship between gut microbiota and CVD, particularly atherosclerosis ${ }^{(125)}$. However, the understanding of this association is still limited. Keeping this in mind, a potential beneficial modulation of intestinal microbiota in a specific manner using probiotics and/or prebiotics might have a cardioprotective role in the host. In this sense, the gut microbiota could represent a new target for the treatment and prevention of CVD, and studies in this field of knowledge may be increasingly promising.

\section{Osteoporosis}

Osteoporosis is a disease characterised by bone mass insufficiency and deterioration of the structural bone tissue, resulting in an increased susceptibility to fractures. The prevention of this public health problem can bring considerable social and economic benefits ${ }^{(126)}$. Among the most important nutrients to obtain a maximum bone mass during the growth phase, $\mathrm{Ca}$ and $\mathrm{Mg}$ are of great importance. Their absorption occurs preferably in the small intestine, although it takes place to a less extent in the large intestine ${ }^{(127,128)}$.

Although the precise mechanism for prebiotic potential effect on osteoporosis is not known, several hypotheses have been proposed to explain the effect of FOS on Ca absorption and retention. One of them is related to the bacteria effect in the colon, as they are able to ferment FOS and other non-digestible carbohydrates, increasing the production of the SCFA (such as butyrate, propionate and acetate) plus other organic acids such as lactic acid. These compounds are able to reduce the $\mathrm{pH}$ through the acidification of the luminal content; thus, under these conditions, insoluble compounds such as $\mathrm{Ca}$ phosphate are dissolved in the lumen (ionised $\mathrm{Ca}$ ), and there is an increased absorption of these compounds by passive diffusion $^{(129)}$. In addition, the SCFA may help increase Ca absorption rates through the exchange between cellular protons and luminal $\mathrm{Ca}^{(130)}$ and through the epithelial cell proliferation stimulation, leading to an increased Ca absorption surface ${ }^{(131)}$.

According to several studies conducted with animals, inulin is the fructans that has the greatest effect on increased $\mathrm{Ca}$ bioavailability ${ }^{(126)}$.

According to Scholz-Ahrens et $a l^{(132)}$, a number of studies have investigated the effect of prebiotics (inulin, oligofructose and other non-digestible carbohydrates) on mineral absorption in humans, but the outcomes were contradictory. This may be related to the experimental conditions evaluated and the physiological characteristics of the target groups included, which may vary considerably among studies.

van der Heuvel et al. ${ }^{(133)}$ and van der Heuvel et al. ${ }^{(134)}$ showed, respectively, that menopausal women who received $10 \mathrm{~g}$ of lactulose or $20 \mathrm{~g}$ of TOS daily had higher levels of absorbed $\mathrm{Ca}$, when compared with their respective controls. According to Coudray et $a l^{(135)}$, young men who consumed $40 \mathrm{~g}$ of inulin daily, over a period of $26 \mathrm{~d}$, showed an increase in the apparent absorption of $\mathrm{Ca}$ of approximately $40 \%$, and this effect did not negatively affect the absorption of other minerals, including $\mathrm{Mg}, \mathrm{Zn}$ and Fe. However, Tahiri et al. ${ }^{(136)}$ conducted a randomised, double-blind, placebo-controlled study with menopausal women to assess the effect of the intake of $10 \mathrm{~g}$ of FOS daily (for 5 weeks) on intestinal Ca absorption and did not observe a significant improved absorption by the FOS group $(35.63 \pm 9.40$ and $36.55 \pm 8.48 \%$ for prebiotic and placebo groups, respectively). Among the possible explanations for this observation, we ought to mention the dose of prebiotics tested, which may have been too low.

It is believed that the effect of prebiotics on minerals bioavailability and trace elements is related to the synthesis of polyamines, which are metabolites produced by various microbial strains ${ }^{(137)}$ and are able to stimulate cell multiplication, consequently leading to an increased absorption surface $^{(138)}$. Furthermore, probiotics are able to produce vitamins, which are required for bone matrix formation and bone growth ${ }^{(139)}$. 
However, most scientific knowledge on the effect of probiotics and prebiotics on mineral metabolism is based on animal studies, generally rats. Therefore, additional studies, particularly human trials, are required for an accurate determination of the effects and mechanisms of the action involved in lowering the risk for osteoporosis through the consumption of probiotics and prebiotics.

\section{Female urogenital health}

The vaginitis caused by yeasts belonging to the Candida genus, the bacterial vaginosis, together with the urinary tract infections, annually affect nearly a billion women around the world ${ }^{(140)}$. The traditional drug treatment for these pathologies often destroys the autochthonous microbiota, frequently selects multidrug-resistant micro-organisms and causes side effects of variable intensities ${ }^{(141)}$. Thus, studies with harmless micro-organisms that have scientifically shown a therapeutic effect can be important tools in the re-establishment of the autochthonous microbiota, which acts as a natural barrier against a number of pathogenic and opportunistic microorganisms.

Lactobacilli are considered the predominant members of the human vaginal microbiota of healthy women in the postpuberty period, forming a biofilm on the surface of the vaginal mucosa ${ }^{(142)}$. These micro-organisms are extremely important in the protection against various infectious agents ${ }^{(143,144)}$. This effect is related to their ability to adhere to the vaginal epithelial cells and to synthesise several inhibitory compounds against vaginal pathogens, including hydrogen peroxide, organic acids, bacteriocins, biosurfactants, auto- and co-aggregation molecules and the arginine deaminase enzyme ${ }^{(145-149)}$.

According to Reid \& Burton ${ }^{(150)}$, the main characteristics necessary for species of the Lactobacillus genus to be used as probiotic cultures in the prevention and/or treatment of urogenital infections include the capacity of adherence to the vaginal epithelial cells, inhibition of adhesion and growth of pathogenic micro-organisms, depletion of nutrients available for pathogens, changing the microenvironment and modulation of the host immune response.

It is believed that lactobacilli exert beneficial effects on the prevention and/or treatment of urogenital infections through one or more different mechanisms, namely (i) ascendance of the probiotic micro-organisms from the rectum to the vagina; (ii) reduction of pathogen transference from the rectum to the vagina; or (iii) increased intestinal mucosal immunity, which acts on the vaginal immunity by making the vaginal tract less susceptible for the colonisation of pathogenic microorganisms $^{(151-153)}$.

The study of the first probiotics for urogenital health, mainly L. rhamnosus GR-1 and $L$. reuteri $\mathrm{RC}-14$ and also $L$. reuteri (formerly fermentum) B-54, began in the $1980 \mathrm{~s}^{(154)}$. The first clinical studies to demonstrate a significant reduction in the incidence of recurrent urinary tract infections in women after intravaginal use of L. rhamnosus GR-1 alone and combined with $L$. reuteri $\mathrm{B}-54$ were published by Bruce \& Reid ${ }^{(155)}$ and Bruce et al. ${ }^{(156)}$.
L. rhamnosus GR-1 and L. reuteri $\mathrm{RC}-14$ were shown to be promising probiotic strains when co-administered with traditional antimicrobial agents for the treatment of vulvovaginal candidiasis $^{(157)}$ and bacterial vaginosis ${ }^{(158,159)}$

With regard to the evaluation of other probiotics, Williams et al. ${ }^{(160)}$ conducted a double-blind, placebo-controlled study in which $L$. acidophilus or clotrimazole were applied intravaginally once a week and it prevented the development of vulvovaginal candidiasis in HIV-positive patients, in comparison with the group of women receiving placebo.

On the other hand, Pirotta et al. ${ }^{(161)}$ conducted a doubleblind, placebo-controlled study with non-pregnant women and reported that L. rhamnosus and B. longum (administered orally) or L. rhamnosus, Lactobacillus delbrueckii, L. acidophilus and $S$. thermophilus (intravaginal use) were not effective in preventing the infection after the treatment with different antimicrobial drugs, in comparison with the control group.

Larsson et $a l^{(162)}$ performed a double-blind, placebo-controlled study in which they observed that the combined use of topical clindamycin and daily vaginal insertion of capsules containing Lactobacillus gasseri Lba EB01-DSM 14869 and L. rhamnosus Lbp PB01-DSM 14870, for a period of $10 \mathrm{~d}$ during three menstrual cycles, did not improve the effectiveness of the bacterial vaginosis therapy during the 1st month of treatment; however, the therapeutic procedure extended the time for the occurrence of relapse, evaluated after 6 months of treatment. On the other hand, Eriksson et $a l^{(163)}$ showed that the co-administration of clindamycin ovules and capsules for vaginal use with lactobacilli (L. fermentum, L. casei-rhamnosus and L. gasseri) did not raise the infection cure rate (62\%), compared with patients who used the antibiotic and capsules containing placebo (56\%).

This inconsistency of results in several clinical studies with the use of potentially probiotic LAB may be partially related to the fact that studies were limited to the effects of a specific microbial strain, to small groups of monitored patients and also to the lack of available data regarding the adequate identification and stability of the micro-organism tested, when capsules, tampons or any other vehicle were used for probiotic delivery. Other important issues when comparing studies published by different authors that assessed the effect of probiotics on urogenital infections include the fact that the micro-organisms' dosages and the periods for both treatment and evaluation of outcomes are normally not uniform. It is also necessary to stress out that when probiotics are co-administered with antibacterial and antifungal agents, the viability of the micro-organisms ought to be previously assessed in vitro so that it can be verified that they are not adversely affected in the presence of these drugs, which could severely impair their efficacy. Thus, it is clear that further, standardised studies are required to conclusively prove the effectiveness of such approaches in the prevention and/or treatment of urogenital infections, especially at a time when few drugs are in the pipeline, and to precisely elucidate precisely the mechanisms of actions involved.

\section{Cavities, periodontal disease and halitosis}

Cavity is one of the most prevalent chronic diseases in the world $^{(164)}$. This pathology, bacterial in origin, has multifactorial 
causes and is characterised by tooth enamel demineralisation ${ }^{(165)}$. This disease occurs after changes in oral ecosystem homoeostasis, resulting in the proliferation of bacterial biofilm, predominantly composed of bacteria belonging to the Streptococcus mutans group ${ }^{(166)}$. To present beneficial effects, limiting or preventing the development of cavities, the potential probiotic micro-organism needs to attach to the dental surface and integrate the bacterial biofilm, where it must compete with cariogenic bacteria, preventing their growth. In addition, as the probiotic micro-organism metabolises sugars obtained from the diet, it is necessary that it produces low acid levels ${ }^{(167)}$.

Various clinical studies have shown that regular consumption of yogurt, milk or cheese containing probiotic cultures leads to the reduction in the number of cariogenic streptococci in saliva and dental plaque ${ }^{(168,169)}$. An interesting study was conducted by Kang et $a l^{(170)}$, in which two microbial strains of Weissella cibaria CMS1 and CMS2, isolated from the saliva of children, showed in vitro inhibitory effect against the formation of dental plaque. The researchers also evaluated seventy-two patients who used an oral rinsing solution containing $10^{9} \mathrm{CFU} / \mathrm{ml}$ of strain CMS1, twice a day, for $1 \mathrm{~d}$, and noted inhibition of dental plaque formation in $20.7 \%$ of the subjects. Even though $W$. cibaria CMS1 reduced the biofilm formation, Kang et al. ${ }^{(170)}$ did not observe any antagonistic activity against $S$. mutans.

Periodontal diseases include gingivitis and periodontitis. The first one is characterised by inflammation confined to the gingival tissue, whereas the periodontitis is a progressive disease, which destroys the teeth support tissues, including the alveolar bone ${ }^{(171)}$. The main micro-organisms associated with the development of gingivitis include Porphyromonas gingivalis, Treponema denticola, Tannerella forsythia and Aggregatibacter actinomycetemcomitans ${ }^{(171)}$. Some studies demonstrated the ability of certain lactobacilli strains to inhibit the growth of pathogens related to the development of periodontal disease ${ }^{(172,173)}$. These observations led researchers to believe that the autochthonous lactobacilli from the oral microbiota could have an important role in this microecosystem balance. Thus, Krasse et al. ${ }^{(174)}$ studied the effect of a chewing gum supplemented with probiotic L. reuteri strains (LR-1 or LR-2), which was administered to volunteers with gingivitis (moderate to severe) during $14 \mathrm{~d}$. The authors observed that the oral cavity of these individuals was colonised by the microorganisms and that they even helped to reduce the dental plaque index scores. Riccia et $a l^{(175)}$ studied the antiinflammatory effects of $L$. brevis $\mathrm{CD} 2$ in a group of patients diagnosed with chronic periodontitis and observed that the micro-organism, administered over a period of $4 \mathrm{~d}$, was able to improve the clinical parameters evaluated (plaque and gingival index scores and bleeding) in all volunteers.

Interestingly, according to a review paper published by Laleman \& Teughels ${ }^{(176)}$, several studies on real periodontitis patients showed a significant reduction of gingivitis and plaque index associated with the use of probiotics, whereas this effect was not observed for experimental gingivitis patients. The authors stated that the pronounced heterogeneity in studies that assessed the efficacy of probiotics on periodontal diseases makes comparison between them difficult. This heterogeneity includes several aspects, such as a very diverse patient population studied (e.g. healthy volunteers, experimental gingivitis models, and patients with gingivitis, chronic and aggressive periodontitis) and a broad range of parameters evaluated (e.g. microbiological determinations in saliva and plaque, various plaque and gingivitis indices, bleeding on probing and probing pocket depth). Laleman \& Teughels ${ }^{(176)}$ highlighted that the clinical studies usually evaluate probiotic use for a short period (up to 3 months), which demonstrates that real periodontal parameters, such as probing pocket depth, are not adequately characterised or are not significantly different from baseline data.

Another example of probiotic application in dental practice is in the treatment of halitosis, a disease that has several causes, including metabolic disorders, consumption of certain types of food and respiratory tract infections. However, most cases of the pathology are associated with an imbalance of the oral cavity commensal microbiota. In fact, halitosis results from the action of anaerobic bacteria that degrade proteins present in the saliva and in the food and, as a consequence, produce amino acids, which are transformed into volatile compounds, responsible for the characteristic halitosis oral malodour ${ }^{(177)}$.

Burton et al. ${ }^{(178)}$ evaluated a group of patients diagnosed with halitosis who were treated with antimicrobials for $3 \mathrm{~d}$ and administered the probiotic organism Streptococcus salivarius K12 supplement for 2 weeks. The researchers noted that most of the volunteers exhibited reduced levels of volatile sulphur compounds (VSC) for at least 2 weeks. In addition, all patients showed increased levels of $S$. salivarius K12 and reduction of the bacterial populations responsible for the oral malodour, both determined in the saliva samples evaluated. Different results were reported by Keller et $a l^{(179)}$, who conducted a randomised placebo-controlled study, in which a probiotic gum containing L. reuteri DSM 17938 and L. reuteri PTA 5289 was used for $14 \mathrm{~d}$ by patients who self-reported malodourous morning breath. The authors concluded that the probiotic gum consumption did not alter VSC levels, even though the organoleptic scores were significantly lower in the probiotic group when compared with the placebo group.

The complex oral microbiota constitutes a major challenge for the prevention and control of cavities, periodontal disease and halitosis using probiotic LAB, although several clinical studies have demonstrated such potential. According to Laleman \& Teughels ${ }^{(176)}$, for future long-term probiotic trials, randomisation and blinding steps should be adequately followed and should include large groups of patients and assess real dental parameters (caries, plaque formation and probing pocket dept) instead of intermediate end points. Furthermore, researchers should carefully investigate strain- and dosespecific effects and evaluate the most appropriate vehicles for their delivery. As substantial scientific evidence demonstrates the usefulness of probiotics on maintenance and/ or improvement of oral health, this approach can be successfully applied in dental practice.

\section{Allergic reactions}

The increasing prevalence of allergic diseases, especially in industrialised countries, has driven the research towards a 
better understanding of the possible causal factors involved, as well as the development of new, safer and more effective treatments ${ }^{(180)}$

The interest in the intestinal microbiota has increased in recent years, especially concerning the role of LAB in the development and prevention of allergic diseases ${ }^{(181,182)}$. Several studies have shown that the composition of the intestinal microbiota and, particularly, the presence of certain species of $\mathrm{LAB}$, is different between healthy children and those suffering from atopic diseases ${ }^{(183-185)}$.

There is a great enthusiasm for human diet supplementation with probiotic LAB for the prevention of allergies, as these micro-organisms are well tolerated and may be appropriate for the protective immune function regulation ${ }^{(180)}$. Certain clinical studies have demonstrated beneficial effect in the prevention of atopic disease in newborn babies, whose mothers had their diets supplemented with probiotic cultures during pregnancy ${ }^{(186,187)}$

Rautava et $a l^{(188)}$ observed that the administration of L. rhamnosus GG to Finnish pregnant women $\left(2 \times 10^{10} \mathrm{CFU}\right.$ of the micro-organism/daily during 4 weeks before giving birth) and throughout breast-feeding (identical dose; otherwise infants received the probiotic) significantly reduced the risk of development of atopic eczema in infants during the first 2 years of life. However, Kopp et al. ${ }^{(189)}$ reported different results using the same probiotic strain. These researchers observed that the administration of the micro-organism to German women during the gestation period $\left(1 \times 10^{10} \mathrm{CFU}\right.$ of L. rhamnosus GG/daily during 4-6 weeks before giving birth) and postnatally (same dose for 6 months; after 3 months, the probiotic was given only to the neonates) did not prevent the development of atopic dermatitis in newborns and also increased the risk of developing bronchitis. These results are important to emphasise the need for the careful selection of bacterial strains and their full characterisation regarding immunomodulatory properties before their use for prophylactic or therapeutic purposes. Moreover, according to Kopp et al ${ }^{(189)}$, when results obtained from clinical trials performed with diverse populations are compared (e.g. volunteers from different nationalities), it is necessary to draw attention to the fact that different genetic backgrounds may also be involved. This observation has a significant role in the final outcomes observed. Finally, the authors concluded that additional studies are necessary to determine whether there are susceptible subgroups of patients, and how they may profit from specific dietetic supplementation with probiotics.

According to a meta-analysis published by Kim et al. ${ }^{(190)}$, probiotics may be considered an option for the treatment of atopic dermatitis, namely for moderate to severe cases of the disease in children and adults, although there is not enough evidence to support their usefulness in infants. The authors also stated that, among the twenty-five randomised controlled trials included in the meta-analysis, differences in probiotic strains and their doses tested, food intake, compliance and medicaments taken simultaneously with the probiotic interventions are important constraints when making robust conclusions. Therefore, improvement of clinical trials design matching these variables (head-to-head comparison) would allow a more fair comparison between outcomes and corroborate (or not) their usefulness in clinical practice.

A study developed by Martinez-Canavate et al. ${ }^{(191)}$ assessed the immunological effects of the consumption of a milk product containing two probiotic strains (L. gasseri CECT5714 and Lactobacillus coryniformis CECT5711) in children with respiratory allergies (asthma, pollen allergy or both). The researchers observed that the volunteers who consumed probiotic cultures showed increased levels of IgA in the mucosa, as well as higher levels of regulatory $\mathrm{CD} 4^{+} / \mathrm{CD} 25^{+}$ $\mathrm{T}$ cells in plasma samples. On the other hand, the researchers found a reduction in the plasma IgE levels in the group supplemented with probiotics and an increased number of natural killer (NK) cells, compared with the group that received the traditional yogurt. The authors concluded that the probiotic cultures reinforced the innate and specific immunity and improved the general status of the children's health.

Another area of great interest in the application of probiotics is related to the prevention of foodborne allergies. It is possible that these micro-organisms are able to reduce intestinal inflammation and therefore improve the clinical features of susceptible patients. A number of studies have been conducted in the last decades to further explore this therapeutic approach $^{(192-194)}$.

Several mechanisms have been proposed to explain the interaction of probiotic LAB with the host's immune system, including the following: stimulation of $\operatorname{IgA}$ secretion in the mucosal surfaces ${ }^{(195)}$; induction of pro-inflammatory or regulatory cytokines production ${ }^{(196-198)}$; modulation of dendritic cell differential maturation ${ }^{(199)}$; and interaction with the immune system through signalling via the 'toll-like receptor' $(\mathrm{TLR})^{(200)}$. In addition, it is important to highlight that the immunogenicity attributed to some probiotic LAB does not necessarily require that these micro-organisms remain viable and survive the passage throughout the GIT ${ }^{(201)}$.

In a general context, there are a limited number of clinical trials that demonstrate positive effects of probiotics on the prevention and/or treatment of allergies, whereas other studies report negative results. Until now, only a limited number of probiotic strains have shown beneficial effects, especially regarding the prevention of allergic diseases. It is important to stress out that this research area is relatively new, since the first intervention trial was reported in $1997^{(192)}$. In general, the available scientific evidence rather reflects the inherent complexity of the allergic syndromes, the characteristics and potential variables of the different probiotic strains tested and the limited understanding of the mechanism by which they can mitigate and/or neutralise different types of immune dysfunction found in allergic diseases ${ }^{(202)}$. Therefore, a larger number of studies will be needed to ensure the effectiveness of the use of LAB probiotic strains with this purpose. According to Kalliomäki et $a l .{ }^{(202)}$, in the future, properly selected probiotic strains for allergic conditions in well-defined specific target populations may become an efficient tool to fight them. The authors also emphasise that clinical trials should use standardised criteria for both diagnosis and symptom scoring, as well as for evaluating the genetic predisposition to allergic diseases. 
The effectiveness of prebiotics on allergic diseases in preterm infants was investigated by Niele et al. ${ }^{(203)}$, who performed a randomised controlled trial in which 113 preterm infants received enteral neutral and acid oligosaccharide supplementation or placebo from day 3 to 30 of life. The authors observed that the incidence of allergic diseases during the 1st year of life was not different between both groups studied. Interestingly, a study published by Schouten et al. ${ }^{(204)}$ demonstrated that a prebiotic mixture containing short-chain GOS and long-chain FOS was able to reduce the cumulative incidence of atopic dermatitis in infants at risk for allergy, in comparison with placebo supplementation.

Anyhow, there is no overall consensus on the effectiveness of this approach, as according to a systematic review published by Williams \& Grindlay $^{(205)}$ there is not yet any substantial evidence of benefit for the use of prebiotics in atopic dermatitis prevention. Furthermore, according to another systematic review made by Osborn \& Sinn ${ }^{(206)}$, more controlled studies are needed before prebiotics can be routinely used for the prevention of allergy in formula-fed infants, even though some evidence exists that prebiotic addition to infant formulas might prevent eczema.

\section{Inflammatory bowel diseases and irritable bowel syndrome}

Inflammatory bowel diseases (IBD) are a group of inflammatory disorders from the GIT with multifactorial aetiology, including ulcerative colitis (UC) and Crohn's disease (CD). UC is characterised by a continuous superficial mucosal inflammation of the colon, whereas in the case of $\mathrm{CD}$ inflammation is discontinuous and most often affects the ileum and the colon, although it may also affect different parts of the GIT. Even though the exact cause of the development of IBD is unknown, the hypothesis usually accepted is that the pathology begins with the loss of oral tolerance in people genetically predisposed, resulting in chronic intestinal inflammation ${ }^{(207)}$.

The first evidence of intestinal microbiota in the development of IBD was obtained from a study of a colitis model, in which inflammatory reaction was observed in germ-free animals ${ }^{(208)}$. Besides the normal intestinal microbiota imbalance, some patients with IBD present an overreacting immune response of commensal micro-organisms, which is believed to be an important factor in the aetiology of the disease. Although the exact mechanisms involved in the loss of oral tolerance have not yet been completely elucidated, some researchers have demonstrated an increased infiltration of activated $\mathrm{CD}^{+}$ lymphocytes in the mucosa, dysfunction of dendritic cells and abnormal immune responses induced by macrophages ${ }^{(209,210)}$.

Besides the possibility of surgical interventions, traditional antibiotics are also used in the treatment of UC and CD. However, these may lead to important side effects, including leukopenia, abnormalities in the liver functions, nephritis and pancreatitis ${ }^{(211)}$. This scenario stimulates the search for new strategies to be used in the appropriate management of these pathologies. Thus, the manipulation of the composition and activity of endogenous intestinal microbiota, in addition to the barrier function and the immune system, have been the main strategies assessed through intervention studies with the use of probiotic micro-organisms. Different mechanisms have been proposed to explain the beneficial effects of probiotics in patients with IBD, which include competition for nutrients and adhesion sites, production of antimicrobial substances and/or cell-cell communication ${ }^{(212)}$. Probiotics may affect the immune system through the interaction of bacterial products, such as cellular components or DNA, with epithelial and immune cells associated with the intestine ${ }^{(213)}$. In addition, some studies have also shown changes in the profile of cytokines produced, modulation on dendritic cells function, increased activity of NK cells and induction of regulatory $\mathrm{T}$ cells and defensins ${ }^{(212-214)}$. Finally, probiotics may contribute towards the production of SCFA, modifying the barrier function by inducing the production of mucin, favouring tight junctions, besides reducing cell apoptosis $^{(215,216)}$.

Following this line, $\mathrm{Ng}$ et al. ${ }^{(217)}$ evaluated in vivo effects of the oral use of a commercial probiotic product VSL $\# 3^{\circledR}$ (L. casei, L. plantarum, L. acidophilus, L. delbrueckii ssp. bulgaricus, B. longum, B. breve, B. infantis and S. thermophilus; Sigma-tau Pharmaceuticals Inc.) and steroids on colonic dendritic cells in patients with acute UC. Rectal biopsies were obtained from patients with active UC before and after treatment with VSL $\# 3^{\circledR}$ and corticosteroids, or placebo, and from healthy controls. The authors showed that treatment of UC patients with probiotic VSL $\# 3^{\circledR}$ and corticosteroids induced favourable intestinal dendritic cell function in vivo, increased the levels of regulatory cytokines and lowered both the levels of pro-inflammatory cytokines and TLR expression. Thus, the researchers suggested that these effects may contribute to therapeutic benefits.

Rahimi et $a l^{(218)}$ published a meta-analysis on eight clinical trials with $\mathrm{CD}$ patients and concluded that probiotics were not effective in maintaining remission and in preventing clinical and endoscopic recurrence of the disease. More recently, a review article published by Shen et $a l^{(219)}$, based on a meta-analysis of twenty-three randomised controlled trials including a total of 1763 subjects, VSL $\# 3^{\circledR}$ was the most effective treatment for the management of UC, whereas its effect on CD was much less pronounced. In fact, meta-analyses are powerful tools to demonstrate scientific evidence; however, they must be used rationally. For instance, when meta-analyses gather data from different probiotics (efficacious and non-efficacious), various conditions, and patients with diverse characteristics, the final result will merely be an average non-effect because of the heterogeneity of the benefits and the probiotics evaluated. Moreover, metaanalyses can also indicate generic activities of micro-organisms instead of the distinct functionality of a particular strain ${ }^{(220)}$.

Irritable bowel syndrome (IBS) is a highly prevalent gastrointestinal disorder, which is difficult to treat and is characterised by a set of complex symptoms ${ }^{(221)}$. Patients with IBS normally have crampy abdominal pain, altered bowel habits, bloating, flatulence and disturbed defecation. These symptoms vary in intensity (mild to severe), but even though IBS is a benign disease its impact on well-being and overall quality of life is notoriously adverse. Moreover, for many subjects, IBS is a chronic condition that follows a course of relapse and remission of symptoms ${ }^{(222,223)}$.

Several researchers have evaluated the use of probiotic micro-organisms in the treatment of IBS; however, the results 
are inconclusive. Some studies demonstrated an overall improvement of symptoms with probiotics, whereas others reported an absence of any beneficial outcomes. Clarke et $a l .{ }^{(223)}$ published a review article on clinical studies with the purpose of determining the efficacy of probiotic LAB in the treatment of IBS. The authors observed that among the forty-two studies examined thirty-four indicated positive effects in at least one of the parameters or symptoms evaluated, although a high variation in the intensity of effects and in the probiotics tested was observed. Clarke et al. ${ }^{(223)}$ also pointed out several problems regarding the type of experimental design used, inadequate selection and doses of probiotic microorganisms, unknown mode of action and scarcity of available data on the tolerance of the ingested micro-organisms during a long period of time, once the pathology is a long-lasting or chronic condition. In spite of these limitations, there seems to be a consensus among specialists in this field that some probiotic LAB are efficient in the treatment of IBS; however, the positive outcomes vary and are related to the time duration of their administration in patients ${ }^{(224-226)}$.

Ringel \& Ringel-Kulka ${ }^{(227)}$ also reviewed the scientific literature on clinical randomised placebo-controlled clinical studies that determined the efficiency of probiotics in the treatment of patients diagnosed with IBS. Similar to the study published by Clarke et al. $^{\text {(223) }}$, Ringel \& Ringel-Kulka ${ }^{(227)}$ observed important differences regarding the experimental design, doses, probiotic strains and parameters used between the different studies reviewed. According to this meta-analysis, as a whole, probiotics were more efficient than placebo in the improvement of IBS symptoms, as well as for the reduction of the risk for persistent symptoms. Whelan ${ }^{(228)}$ highlighted that meta-analysis is a valuable tool to gather individual small trials to improve the ability to determine the direction, size and consistency of an effect; however, it can do little to overcome the poor design of individual trials, frequently seen for the management of IBS with probiotics. The author also recommended that all future meta-analyses on probiotics ought to include a subgroup of analyses on specific combinations (species/strains).

Overall, according to reviewed and meta-analysed data, bifidobacteria, lactobacilli, Escherichia coli, E. faecalis and a mixture of bacterial strains were the most promising microorganisms for the management of IBS. However, there is no strict consensus on the rationale use of the approach, attributed to the lack of knowledge of their exact mechanisms of action (via intestinal immune system, enteric nervous system or otherwise), complexity of the disease (variable course of symptoms and heterogeneity) and high placebo responses observed in clinical trials on IBS (up to $50 \%)^{(229)}$.

Two studies that addressed the positive outcomes obtained with interventions carried out using probiotics in the treatment of IBS should be mentioned. One of them was published by O'Mahony et al. ${ }^{(230)}$ and evaluated the use of B. infantis 35624 or Lactobacillus salivarius UCC4331 v. placebo in the treatment of the pathology. The researchers observed a significant improvement in the symptoms (pain reduction, less bloating and reduced intestinal motility) in the group that received B. infantis 35624, in comparison with the placebo group. Whorwell et al. ${ }^{(231)}$ conducted a multi-centre study and confirmed these results by the observation that patients diagnosed with IBS supplemented during 4 weeks with B. infantis 35624 exhibited significant reduced pain and an overall improvement of IBS symptoms, compared with the subjects who received placebo.

According to Bonfrate et al. ${ }^{(232)}$, only a limited number of clinical trials have assessed the effect of prebiotics on IBS patients. Among them, Hunter et al. ${ }^{(233)}$ performed a doubleblind crossover study with patients suffering from IBS who received, three times daily, $2 \mathrm{~g}$ of oligofructose (Raftilose P95; Orafti) or $1 \mathrm{~g}$ of sucrose, both administered during 4 weeks. The researchers observed that the prebiotic tested did not alter any of the parameters studied (faecal weight and $\mathrm{pH}$, whole-gut transit time, and fasting breath hydrogen concentrations) and, therefore, concluded that oligofructose given at a dose of $6 \mathrm{~g} / \mathrm{d}$ presented no therapeutic value in patients diagnosed with the disease. Olesen \& Gudmand-Hoyer ${ }^{(234)}$ performed a multicentre, double-blind randomised placebo-controlled study and reported no significant differences in the severity and duration of symptoms (abdominal distension, abdominal rumbling, abnormal flatulence and abdominal pain) in IBS patients who received $20 \mathrm{~g}$ of FOS powder daily for 12 weeks, compared with those who had taken placebo.

On the other hand, Silk et $a l .{ }^{(235)}$ investigated the effect of a novel prebiotic TOS on IBS patients. The authors evaluated a group of forty-four subjects diagnosed with the disease who were randomised to receive the prebiotic $(3.5$ or $7 \mathrm{~g} / \mathrm{d})$ or placebo $(7 \mathrm{~g} / \mathrm{d})$ and observed that prebiotics increased the bifidobacteria populations in the faecal samples collected throughout the study. Silk et al. ${ }^{(235)}$ also reported that although the lowest dosage of the prebiotic significantly changed stool consistency, improved bloating, flatulence and subjective global assessment (SGA), the highest dosage of the prebiotic improved SGA and anxiety scores. Finally, Andriulli et al. ${ }^{(236)}$ evaluated the efficacy of a product called Flortec (Anidral Co.), containing a mixture of prebiotics and probiotic Lactobacillus paracasei B21060 in people diagnosed with IBS. The authors conducted a multicentre, randomised study in which patients received the prebiotic or Flortec, and observed that in IBS-predominant diarrhoea the latter significantly reduced bowel movements, abdominal pain and IBS scores. As shown above, different types of prebiotics have been administered at distinct doses and time periods, which make the comparison between the results of the various studies and the final decision of which one(s) is (are) the most promising to treat the disease particularly hard if not impossible.

Considered altogether, the scientific evidences on the probiotic effects are less contradictory in the case of UC, whereas for $\mathrm{CD}$ the available results are still scarce and not so encouraging ${ }^{(237)}$. As for other diseases, the number of clinical studies that evaluate the effects of probiotics and prebiotics on IBD and IBS is still limited, which justifies the necessity of conducting new rigorous, long-term, well-planned, randomised clinical studies in this field of knowledge ${ }^{(86,238)}$. Particularly for IBS clinical trials, substantial clinical outcomes should include the evaluation of symptom improvement with psychometrically validated SGA or validated symptom severity questionnaires $^{(229)}$. 


\section{Helicobacter pylori gastric infections}

Helicobacter pylori infection may lead to chronic gastritis, and it constitutes the leading cause of peptic ulcer disease, besides being a risk factor for the development of gastric cancer ${ }^{(239)}$. Currently, there is a remarkable interest in the development of low-cost and large-scale solutions to prevent or reduce the gastric colonisation by $H$. pylori. In this context, probiotics become an especially interesting approach.

Several clinical studies have shown the beneficial effect of Lactobacillus johnsonii La1 on gastritis caused by $H$. pylori. Michetti et al. ${ }^{(240)}$ noted that the administration of L. jobnsonii La1 culture supernatant suppressed the pathogen urease activity in asymptomatic volunteers. The researchers observed that the effect remained for 6 weeks after the end of the treatment, although the suppression of $H$. pylori urease activity was not intensified by the co-administration with omeprazole. In reality, $H$. pylori is known to catalyse the conversion of urea to dioxide and ammonia. The latter is then turned into ammonium hydroxide neutralising the local acidity, which favours the pathogen survival ${ }^{(241)}$. Felley et al. ${ }^{(242)}$ observed that patients diagnosed with $H$. pylori infection (evidenced by histological examination of the gastric biopsies), treated with clarithromycin and supplemented with preparations of milk containing L. johnsonii La-1, showed a reduction of both the infection intensity and the pathogen density in the tissue sample. The authors highlighted that such effects persisted for several weeks after the end of the probiotic intake period. Pantoflickova et $a l .{ }^{(243)}$ observed that the treatment with the strain L. jobnsonii La1, administered over a period of 16 weeks and without any antibiotic treatment, reduced the intensity of gastritis associated with $H$. pylori, as well as the pathogen density determined in the gastric antrum. The authors reported that the positive effects related to the probiotic administration were obtained 3 weeks after the beginning of treatment and remained throughout the period of L. johnsonii La-1 intake.

Wang et al. ${ }^{(244)}$ observed a positive effect regarding the reduction of the gastric infection symptoms and colonisation by H. pylori when probiotic strains L. acidophilus La-5 and B. animalis $\mathrm{Bb}-12$ were tested in patients diagnosed for gastritis.

Lionetti et al. ${ }^{(245)}$ evaluated a $H$. pylori-positive paediatric population (forty subjects; mean age 12.3 years old) who received omeprazole and amoxicillin during $5 \mathrm{~d}$, followed by omeprazole, clarithromycin and tinidazole for another $5 \mathrm{~d}$ and were then randomised to receive pills containing the probiotic strain L. reuteri ATCC 55730 or placebo. The authors reported a significant reduction of gastrointestinal symptoms in the probiotic group, when compared with children supplemented with placebo. Lionetti et al. ${ }^{(245)}$ concluded that the probiotic strain tested was effective in reducing the frequency and intensity of antibiotic-associated side effects during $H$. pylori eradication therapy.

Francavilla et al. ${ }^{(246)}$ studied a group of 100 patients infected with $H$. pylori who received a combination of probiotic strains (L. reuteri DSM 17938 and L. reuteri ATCC PTA 6475) or placebo during a three-phase study (pre-eradication phase - days 0-28; eradication treatment - days 29-35; and follow-up - days
36-96). The authors observed that the probiotics tested demonstrated an inhibitory effect on the pathogen growth; however, when L. reuteri DSM 17938 and L. reuteri ATCC PTA 6475 were associated with the eradication therapy (clarithromycin-amoxicillin for $7 \mathrm{~d}$ ), significantly increased eradication rates (about 9\%) and reduction of both gastrin-17 and antibiotic-associated side effects were found.

Several mechanisms could explain the decreased H. pylori density and the reduction in the inflammatory reaction caused by the pathogen by using probiotic cultures, administered alone or co-administered with antibiotics. Among them, the strengthening of the gastric mucosa immune defences and the increase in the specific and non-specific immune response have important roles ${ }^{(239,247)}$. Moreover, some LAB (L. gasseri Chen and L. plantarum 18) were shown to inhibit $H$. pylori adherence to gastric epithelial cells ${ }^{(248)}$. In fact, H. pylori colonise the mucus layer in the stomach, mostly adhering to epithelial cells. As the chances for probiotic micro-organisms to arrive at this site in significant amounts are extremely reduced, it seems more feasible that, at least for therapeutic purposes, probiotics present an indirect and non-specific instead of a direct and specific anti- $H$. pylori activity ${ }^{(241)}$.

On the other hand, Navarro-Rodriguez et al. ${ }^{(249)}$ reported that a probiotic compound containing L. acidophilus, L. rhamnosus, B. bifidum and Streptococcus faecium $\left(1.25 \times 10^{9} \mathrm{CFU}\right.$ each) administered for $30 \mathrm{~d}$ to patients with peptic ulcer or functional dyspepsia because of $H$. pylori infection, who were previously treated with furazolidone, tetracycline and lansoprazole for $7 \mathrm{~d}$, did not increase the efficacy nor improved the adverse effects of the treatment, when compared with patients supplemented with placebo. Along this line, an interesting study conducted by Szajewska et al. ${ }^{(250)}$ demonstrated that $S$. boulardii supplementation showed limited effect on the H. pylori eradication rate. However, the authors reported that the probiotic reduced the adverse effects related to the drug therapy.

According to a meta-analysis published by Zhang et al. ${ }^{(251)}$, the co-administration of probiotics and antimicrobial agents was associated with an increased $H$. pylori eradication rate and reduction of the adverse effects; however, patient compliance was not improved, which may be related to innate personality features. The authors also highlighted the fact that not all publications include in their clinical studies important subgroups such as patients infected with antibiotic-resistant H. pylori treated with probiotics, which are of great importance for clinical practice. According to Ruggiero ${ }^{(241)}$, the diverse results obtained from different clinical trials reflect the diversity of both probiotic strains and antibiotic agents tested (including respective doses and time periods of administration), as well as the variation in geographic areas that are related to distinct H. pylori strain distribution, host susceptibility and therapy efficacy. The author also emphasised that these variables make a direct comparison of the results obtained from single studies impractical; however, the global findings represent a valuable knowledge on the possible efficacy of probiotic use.

Thus, long-term placebo-controlled clinical studies, considering standardised patients traits such as age, gravity of infection and types of gastrointestinal symptoms, among others, and involving a larger number of volunteers, are still required to 
clarify the real benefits of the co-administration of probiotics and antimicrobials for an adequate treatment of $H$. pylori gastric infections. Interestingly, according to Ruggiero ${ }^{(241)}$, in order to determine the efficacy of probiotics in the management of the disease, specific studies targeting H. pylori (strain-specific infectivity potential) and the host (genetic background and microbiome) are of great importance.

\section{Conclusion}

The field of probiotics and prebiotics has substantially advanced in recent years, stimulated by progress in the comprehension of the role of the human microbiota in health and diseases. Therefore, future investigations that set effective strategies to shape a healthier microbiota, which might help in our physiology and disease processes, will be increasingly stimulated and represent a potentially fruitful area of scientific research. Although there are numerous studies described in the scientific literature regarding the beneficial effects obtained from the consumption of probiotics and/or prebiotics, health claim restrictions on them are made by authorities worldwide, especially in Europe ${ }^{(252)}$. These effects are observed both in the GIT (prevention and/or treatment of gastric and intestinal infections, IBD and IBS) and in other sites (prevention and/or treatment of respiratory tract infections, CVD, osteoporosis, urogenital tract infections, oral cavity infectious diseases and atopic allergy). It is noteworthy that the effects, as well as the mechanisms of action involved, are considered strain specific. The selection of probiotic strains should be directed to the desired effects shown by the micro-organisms of interest, supported by in vitro and in vivo assays, when tested alone or incorporated into a food matrix or a pharmaceutical preparation. Thus, the probiotic strains used for production and the industrial large-scale processing should be adequately characterised and appropriate for each type of product in which they will be delivered, including high viability throughout the storage period and scientific-based evidence for specific health claims.

The improvement of probiotic and prebiotic component application to support human health relies on a better understanding of their mode of action. This clarification will enable further advances in probiotic and prebiotic research and will undoubtedly contribute to the appropriate use of these functional products. In fact, the elucidation of the mechanisms underlying the human microbiota and immune system modulation by probiotics and prebiotics will heavily depend on continuous efforts (massive financial support) to identify appropriate biomarkers of health and diseases risk factors that might improve the design of human trials required for health claim verification. Moreover, large and long-term better-aligned clinical studies in humans are required to provide more reliability and a more solid basis for the results achieved. Systematic reviews and meta-analyses are crucial means to assess the strength of scientific evidence for health effects attributed to the consumption of probiotics and prebiotics and should therefore be acceptable by the EFSA in order to substantiate health claims ${ }^{(253)}$. Although it is important to emphasise that even in case specific health claims would be accepted by EFSA, probiotic and prebiotic food manufacturers are not currently allowed to include these substantiated health claims on the food product label, as that is not the purpose of the consumption of functional foods and only the claims related to the reduction of risk for disease are accepted worldwide.

At the moment, the accumulated knowledge of the beneficial effects of probiotics indicates that the strongest evidence for their efficacy, among all the possibilities discussed in this review article, is that related to the prevention and/or management of intestinal infections, although no definite conclusions can be made. In fact, the inconsistency among studies, which may have a large number of variables, for example, the study design itself, the probiotic strain used, outcome parameters, the population studied and the still limited number of clinical studies are undoubtedly hurdles that have to be overcome ${ }^{(60)}$.

Innovative, safe and cost-effective interventions, for instance, the use of probiotics as toxin scavengers, especially metals present in high levels in the bloodstream ${ }^{(254)}$, is only one example of the feasible accomplishments to be achieved in the near future in this research area. The accelerated production of scientific knowledge related to the effects of probiotics and prebiotics on consumer health tends to result in an extraordinary increase in the range of options of this class of functional foods, especially for those individuals who wish health benefits to be associated to sensory appeal. This scenario makes this niche market highly competitive and profitable.

\section{Acknowledgements}

The authors would like to thank John Milton for the final English review.

This work was supported by Fundação de Amparo à Pesquisa do Estado de São Paulo (FAPESP) (S. M. I. S., financial support grant numbers 2009/51169-0 and 2013/50506-8, R. B., fellowship grant number 2009/51168-3, R. C. R. M., fellowship grant number 2010/52267-2) and Conselho Nacional de Desenvolvimento Científico e Tecnológico (CNPq) (S. M. I. S., fellowship grant no. 305181/2013-0). FAPESP and CNPq had no role in design, analysis or writing of this article.

R. C. R. M. and R. B. carried out the scientific literature search and wrote the review. S. M. I. S. revised the paper critically for important intellectual content, included some information and opinions and suggested several improvements.

There are no conflicts of interest.

\section{References}

1. Laparra JP \& Sanz Y (2010) Interactions of gut microbiota with functional food components and nutraceuticals. Pharmacol Res 61, 219-225.

2. Aureli P, Capurso L, Castellazzi AM, et al. (2011) Probiotics and health: an evidence-based review. Pharmacol Res $\mathbf{6 3}$, 366-376.

3. Ley RE, Lozupone CA, Hamady M, et al. (2008) Worlds within worlds: evolution of the vertebrate gut microbiota. Nat Rev Microbiol 6, 776-788.

4. Booijink CCGM, Zoetendal EG, Kleerebezem M, et al. (2007) Microbial communities in the human small 
intestine-coupling diversity to metagenomics. Future Microbiol 2, 285-295.

5. Zoetendal EG, Rajilic-Stojanovic M \& De Vos WM (2008) High throughput diversity and functionality analysis of the gastrointestinal tract microbiota. Gut 57, 1605-1615.

6. Tap J, Mondot S, Levenez F, et al. (2009) Towards the human intestinal microbiota phylogenetic core. Environ Microbiol 11, 2574-2584.

7. Phillips ML (2009) Gut reaction: environmental effects on the human microbiota. Environ Health Perspect 117, 198-205.

8. Turnbaugh PJ, Hamady M, Yatsunenko T, et al. (2009) A core gut microbiome in obese and lean twins. Nature 457, 480-484.

9. Qin J, Li R, Raes J, et al. (2010) A human gut microbial gene catalogue established by metagenomic sequencing. Nature 464, 59-65.

10. Tremaroli V \& Bäckhed F (2012) Functional interactions between the gut microbiota and host metabolism. Nature 489, 242-249.

11. Zhang J, Guo Z, Xue Z, et al. (2015) A phylo-functional core of gut microbiota in healthy young Chinese cohorts across lifestyles, geography and ethnicities. ISME J 9, 1979-1990.

12. Hill MJ (1997) Intestinal flora and endogenous vitamin synthesis. Eur J Cancer Prev 6, 43-45.

13. Pryde SE, Duncan SH \& Hold GL (2002) The microbiology of butyrate formation in the human colon. FEMS Microbiol Lett 217, 133-139.

14. Tappenden KA \& Deutsch AS (2007) The physiological relevance of the intestinal microbiota - contributions to human health. J Am Coll Nutr 26, 679-683.

15. Resta SC (2009) Effects of probiotics and commensals on intestinal epithelial physiology: implications for nutrient handling. J Physiol 587, 4169-4174.

16. Saulnier DM, Kolida S \& Gibson GR (2009) Microbiology of the human intestinal tract and approaches for its dietary modulation. Curr Pharm Des 15, 1403-1414.

17. Round JL \& Mazmanian SK (2009) The gut microbiota shapes intestinal immune responses during health and disease. Nat Rev Immunol 9, 313-323.

18. Scanlan PD, Shanahan F, O'Mahony C, et al. (2006) Cultureindependent analyses of temporal variation of the dominant fecal microbiota and targeted bacterial subgroups in Crohn's disease. J Clin Microbiol 44, 3980-3988.

19. Cani PD \& Delzenne NM (2009) The role of the gut microbiota in energy metabolism and metabolic disease. Curr Pharm Des 15, 1546-1558.

20. Davis CD \& Milner JA (2009) Gastrointestinal microflora, food components and colon cancer prevention. I Nutr Biochem 20, 743-752.

21. Caesar R, Fak F \& Bäckhed F (2010) Effects of gut microbiota on obesisty and atherosclerosis via modulation of inflammation and lipid metabolism. J Inter Med 268, 320-328.

22. Gerritsen J, Smidt H, Rijkers GT, et al. (2011) Intestinal microbiota in human health and disease: the impact of probiotics. Genes Nutr 6, 209-240.

23. Ley RE, Peterson DA \& Gordon JI (2006) Ecological and evolutionary forces shaping microbial diversity in the human intestine. Cell 124, 837-848.

24. Ross RP, Mills S, Hill C, et al. (2010) Specific metabolite production by gut microbiota as a basis for probiotic function. Int Dairy J 20, 269-276.

25. Scott KP, Gratz SW, Sheridan PO, et al. (2013) The influence of diet on the gut microbiota. Pharmacol Res 69, 52-60.

26. O'Shea EF, Cotter PD, Stanton C, et al. (2012) Production of bioactive substances by intestinal bacteria as a basis for explaining probiotic mechanisms: bacteriocins and conjugated linoleic acid. Int J Food Microbiol 152, 189-205.
27. Peterson CT, Sharma V, Elmén S, et al. (2015) Immune homeostasis, dysbiosis and therapeutic modulation of the gut microbiota. Clin Exp Immunol 179, 363-377.

28. McNulty NP, Yatsunenko T, Hsiao A, et al. (2011) The impact of a consortium of fermented milk strains on the gut microbiome of gnotobiotic mice and monozygotic twins. Sci Transl Med 3, 106ra106.

29. Rauch M \& Lynch SV (2012) The potential for probiotic manipulation of the gastrointestinal microbiome. Curr Opin Biotechnol 23, 192-201.

30. Hill C, Guarner F, Reid G, et al. (2014) The International Scientific Association for Probiotics and Prebiotics consensus statement on the scope and appropriate use of the term probiotic. Nat Rev Gastroenterol Hepatol 11, 506-514.

31. Stolaki M, De Vos W, Kleerebezem M, et al. (2012) Lactic acid bacteria in the gut. In Lactic Acid Bacteria: Microbiological and Functional Aspects, pp. 385-401 [S Lahtinen, AC Ouwehand, S Salminen and A Von Wright, editors]. Boca Raton, FL: CRC.

32. Tannock GW (1998) Studies on the intestinal microflora: a prerequisite for the development of probiotics. Int Dairy J 8, 527-533.

33. Kolida S \& Gibson GR (2011) Synbiotic in health and disease. Annu Rev Food Sci Technol 2, 373-393.

34. Champagne CP, Ross RP, Saarela M, et al. (2011) Recommendations for viability assessment of probiotics as concentrated cultures and in food matrices. Int $J$ Food Microbiol 149, 185-193.

35. Agência Nacional De Vigilância Sanitária (Brazilian Health Surveillance Agency) (2008) Alimentos com alegações de propriedades funcionais e ou de saúde, novos alimentos/ ingredientes, substâncias bioativas e probióticos: lista de alegações de propriedade funcional aprovadas. Atualizado em julho, 2008. (Foods with allegation of functional and/or health properties, new foods/ingredients, bioactive compounds and probiotics: list of allegations of approved functional properties. Up-dated in 2008) http://www.anvisa.gov. br/alimentos/comissoes/tecno_lista_alega.htm (accessed August 2009).

36. Health Canada (2009) Accepted claims about the nature of probiotic microorganisms in foods. http://www.hc-sc.gc.ca/ fn-an/label-etiquet/claims-reclam/probiotics_claims-allegations_ probiotiques-eng.php (accessed October 2014).

37. Ministero della Salute, Commissione unica per la nutrizione e la dietetica (2013) Guidelines on probiotics and prebiotics. http://www.salute.gov.it/imgs/C_17_pubblicazioni_1016 allegato.pdf (accessed October 2014).

38. Lee YK \& Salminen S (2009) Handbook of Probiotics, 2nd ed. Hoboken, NJ: John Wiley \& Sons.

39. Gibson GR, Probert HM, Van Loo JAE, et al. (2004) Dietary modulation of the human colonic microbiota: updating the concept of prebiotics. Nutr Res Rev 17, 259-275.

40. Gibson GR, Scott KP, Rastall RA, et al. (2010) Dietary prebiotics: current status and new definition. Food Sci Technol Bull: Funct Foods 7, 1-19.

41. Rastall RA (2010) Functional oligosaccharides: application and manufacture. Annu Rev Food Sci Technol 1, 305-339.

42. Roberfroid M (2007) Prebiotic: the concept revisited. J Nutr 137, 830-837.

43. Broekaert WF, Courtin CM, Verbeke K, et al. (2011) Prebiotic and other health-related effects of cereal-derived arabinoxylans, arabinoxylan-oligosaccharides, and xylooligosaccharides. Crit Rev Food Sci Nutr 51, 178-194.

44. Crittenden RG, Morris LF, Harvey ML, et al. (2001) Selection of a Bifidobacterium strain to complement resistant starch in a synbiotic yoghurt. J Appl Microbiol 90 , $268-278$. 
45. Topping DL, Fukushima M \& Bird AR (2003) Resistant starch as a prebiotic and synbiotic: state of the art. Proc Nutr Soc 62, 171-176.

46. Figueroa-González I, Quijano G, Ramírez G, et al. (2011) Probiotics and prebiotics - perspectives and challenges. J Sci Food Agric 91, 1341-1348.

47. Topping DL \& Clifton PM (2001) Short-chain fatty acids and human colonic function: roles of resistant starch and nonstarch polysaccharides. Physiol Rev 81, 1031-1064.

48. Crittenden R \& Playne M (2009) Prebiotics. In Handbook of Probiotics and Prebiotics, pp. 535-581 [YK Lee and S Salminen, editors]. Hoboken, NJ: John Wiley \& Sons.

49. Holzapfel WH \& Schillinger U (2002) Introduction to pre- and probiotics. Food Res Int 35, 109-116.

50. Puupponen-Pimiä R, Aura AM, Oksman-Caldentey KM, et al. (2002) Development of functional ingredients for gut health. Trends Food Sci Technol 13, 3-11.

51. Mattila-Sandholm T, Myllärinen P, Crittenden R, et al. (2002) Technological challenges for future probiotic foods. Int Dairy J 12, 173-182.

52. Bielecka M, Biedrzycka E \& Majkowska A (2002) Selection of probiotics and prebiotics for synbiotics and confirmation of their in vivo effectiveness. Food Res Int 35, 125-131.

53. Sanders ME \& Marco ML (2010) Food formats for effective delivery of probiotics. Annu Rev Food Sci Technol 1, 65-85.

54. Rolfe RD (2000) The role of probiotic cultures in the control of gastrointestinal health. J Nutr 130, 396-402.

55. Saad SMI (2006) Probióticos e prebióticos: o estado da arte (Probiotics and prebiotics: the state of the art). Revista Brasileira de Ciências Farmacêuticas 42, 1-16.

56. de Vrese M \& Marteau PR (2007) Probiotics and prebiotics: effects on diarrhea. J Nutr 137, 803-811.

57. Saad N, Delattre C, Urdaci M, et al. (2013) An overview of the last advances in probiotic and prebiotic field. $L W T-$ Food Sci Technol 50, 1-16.

58. Floch MH, Walker WA, Madsen K, et al. (2011) Recommendations for probiotic use: 2011 update. J Clin Gastroenterol 45, 168-171.

59. Guandalini S (2011) Probiotics for prevention and treatment of diarrhea. J Clin Gastroenterol 45, 149-153.

60. Wolvers D, Antoine JM, Myllyluoma E, et al. (2010) Guidance for substantiating the evidence for beneficial effects of probiotics: prevention and management of infections by probiotics. J Nutr 140, 698-712.

61. Arvola T, Laiho K, Torkkeli S, et al. (1999) Prophylactic Lactobacillus GG reduces antibiotic-associated diarrhea in children with respiratory infections: a randomized study. Pediatrics 104, e64.

62. Vanderhoof JA, Whitney DB, Antonson DL, et al. (1999) Lactobacillus GG in the prevention of antibiotic-associated diarrhea in children. $J$ Pediatr 135, 564-568.

63. Marchand J \& Vandenplas Y (2000) Microorganisms administered in the benefit of the host: myths and facts. Eur J Gastroenterol Hepatol 12, 1077-1088.

64. Dendukuri N, Costa V, McGregor M, et al. (2005) Probiotic therapy for the prevention and treatment of Clostridium difficile-associated diarrhea: a systematic review. CMAJ 173, 167-170.

65. Roberfroid M, Gibson GR, Hoyles L, et al. (2010) Prebiotic effects: metabolic and health benefits. Br J Nutr 104, 1-63.

66. Thompson I (2008) Clostridium difficile-associated disease: update and focus on non-antibiotic strategies. Age Ageing 37, 14-18.

67. Kale-Pradhan PB, Jassal HK, et al. (2010) Role of Lactobacillus in the prevention of antibiotic-associated diarrhea: a meta-analysis. Pharmacotherapy 30, 119-126.
68. Hickson M, D'Souza AL, Muthu N, et al. (2007) Use of probiotic Lactobacillus preparation to prevent diarrhoea associated with antibiotics: randomised double blind placebo controlled trial. BMJ 335, 80.

69. Pozzoni P, Riva A, Bellatore AG, et al. (2012) Saccharomyces boulardii for the prevention of antibiotic-associated diarrhea in adult hospitalized patients: a single-center, randomized, double-blind, placebo-controlled trial. Am J Gastroenterol 107, 922-931.

70. Gorbach SL (2000) Probiotics and gastrointestinal health. Am J Gastroenterol 95, 14-18.

71. Goldin BR \& Gorbach SL (2008) Clinical indications for probiotics: an overview. Clin Infect Dis 46, 96-100.

72. Graul T, Cain AM \& Karpa KD (2009) Lactobacillus and bifidobacteria combinations: a strategy to reduce hospitalacquired Clostridium difficile diarrhea incidence and mortality. Med Hypotheses 73, 194-198.

73. Thomas MR, Litin SC, Osmon DR, et al. (2001) Lack of effect of Lactobacillus GG on antibiotic-associated diarrhea: a randomized, placebo-controlled trial. Mayo Clin Proc $\mathbf{7 6}$, 883-889.

74. Balakrishnan M \& Floch MH (2012) Prebiotics, probiotics and digestive health. Curr Opin Clin Nutr Metab Care 15, 580-585.

75. European Food Safety Authority (2010) Scientific opinion on the substantiation of a health claim related to fermented milk containing Lactobacillus casei DN-144 001 plus yoghurt symbiosis $\left(\right.$ Actimel $^{\circledR}$ ), and reduction of Clostridium difficile toxins in the gut of patients receiving antibiotics and reduction risk of acute diarrhoea in patients receiving antibiotics pursuant to Article 14 of Regulation (EC) No 1924/ 2006. EFSA J 8, 1903.

76. Lewis S, Burmeister S \& Brazier J (2005) Effect of the prebiotic oligofructose on relapse of Clostridium difficileassociated diarrhoea: a randomized, controlled study. Clin Gastroenterol Hepatol 3, 442-448.

77. Parashar UD, Gibson CJ, Bresse JS, et al. (2006) Rotavirus and severe childhood diarrhea. Emerg Infect Dis 12, 304-316.

78. Salim AF, Phillips AD \& Farthing MJ (1990) Pathogenesis of gut virus infection. Baillières Clin Gastroenterol $\mathbf{4}$, 593-607.

79. Kaila M, Isolauri E, Soppi E, et al. (1992) Enhancement of the circulating antibody secreting cell response in human diarrhea by a human Lactobacillus strain. Pediatr Res $\mathbf{3 2}$, 141-144.

80. Saavedra JM, Bauman NA, Oung L, et al. (1994) Feeding of Bifidobacterium bifidum and Streptococcus thermophilus to infants in hospital for prevention of diarrhoea and shedding of rotavirus. Lancet 344, 1046-1049.

81. Sugita T \& Togawa M (1994) Efficacy of Lactobacillus preparation Biolactis powder in children with rotavirus enteritis. Jpn J Pediatr 47, 2755-2762.

82. Shornnikova AV, Casas I, Mykkanen H, et al. (1997) Bacteriotherapy with Lactobacillus reuteri in rotavirus gastroenteritis. Pediatr Infect Dis J 16, 1103-1107.

83. van Baarlen P, Troost F, Van der Meer C, et al. (2011) Human mucosal in vivo transcriptome responses to three lactobacilli indicate how probiotics may modulate human cellular pathways. Proc Natl Acad Sci U S A 108, 4562-4569.

84. Hilton E, Kolakowski P, Singer C, et al. (1997) Efficacy of Lactobacillus GG as a diarrheal preventive in travelers. J Travel Med 4, 41-43.

85. Oksanen PJ, Salminen S, Saxelin M, et al. (1990) Prevention of travellers' diarrhoea by Lactobacillus GG. Ann Med 22, 53-56. 
86. Lyra A, Lahtinen S \& Ouwehand AC (2012) Gastrointestinal benefits of probiotics: clinical evidence. In Lactic Acid Bacteria: Microbiological and Functional Aspects, pp. 509-523 [S Lahtinen, AC Ouwehand, S Salminen and A Von Wright, editors]. Boca Raton, FL: CRC.

87. McFarland LV (2007) Meta-analysis of probiotics for the prevention of traveler's diarrhea. Travel Med Infect Dis 5, 97-105.

88. Drakoularakou A, Tzortis G, Rastall RA, et al. (2010) A double-blind, placebo-controlled, randomized human study assessing the capacity of a novel galactooligosaccharide mixture in reducing traveller's diarrhoea. Eur J Clin Nutr 64, 146-152.

89. Cummings JH, Christie S \& Cole TJ (2001) A study of fructo oligosaccharides in the prevention of traveller's diarrhoea. Aliment Pharmacol Ther 15, 1139-1145.

90. Virk A, Mandrekar J, Berbari EF, et al. (2013) A randomized, double blind, placebo-controlled trial of an oral synbiotic (AKSB) for prevention of traveler's diarrhea. J Travel Med 20, 88-94.

91. Vouloumanou EK, Makris GC, Karageorgopoulos DE, et al. (2009) Probiotics for the prevention of respiratory tract infections: a systematic review. Int $J$ Antimicrob Agents 34, 197.

92. Thompson M, Vodicka TA, Blair PS, et al. (2013) Duration of symptons of respiratory tract infections in children: systematic review. BMJ 347, f7027.

93. Snow V, Mottur-Pilson C \& Gonzales R (2001) American College of Physicians-American Society of Internal Medicine, American Academy of Family Physicians, Centers for Disease Control, \& Infectious Diseases Society of America. Principles of appropriate antibiotic use for treatment of nonspecific upper respiratory tract infections: background. Ann Inter Med 134, 487-489.

94. Aguilar L, Giménez MJ \& Barberán J (2010) Drug resistance in community-acquired respiratory tract infections: role for an emerging antibacterial. Infect Drug Resist 3, 35-43.

95. Cangemi de Gutierrez R, Santos V \& Nader-Macias ME (2001) Protective effect of intranasally inoculated Lactobacillus fermentum against Streptococcus pneumoniae challenge on the mouse respiratory tract. FEMS Immunol Med Microbiol 31, 187-195.

96. Yasui H, Kiyoshima J \& Hori T (2004) Reduction of influenza virus titer and protection against influenza virus infection in infant mice fed Lactobacillus casei Shirota. Clin Diagn Lab Immunol 11, 675-679.

97. Racedo S, Villena J, Medina M, et al. (2006) Lactobacillus casei administration reduces lung injuries in a Streptococcus pneumoniae infection in mice. Microbes Infect $\mathbf{8}$, 2359-2366.

98. King S, Glanville J, Sanders ME, et al. (2014) Effectiveness of probiotics on the duration of illness in healthy children and adults who develop common acute respiratory infectious conditions: a systematic review and meta-analysis. Br J Nutr 112, $41-54$

99. Arslanoglu S, Moro GE \& Boehm G (2007) Early supplementation of prebiotic oligosaccharides protects formula-fed infants against infections during the first 6 months of life. J Nutr 137, 2420-2424.

100. Luoto R, Ruuskanen O, Waris M, et al. (2014) Prebiotic and probiotic supplementation prevents rhinovirus infections in preterm infants: a randomized, placebo-controlled trial. J Allergy Clin Immunol 133, 405-413.

101. Puccio G, Cajozzo C, Meli F, et al. (2007) Clinical evaluation of a new formula for infants containing live Bifidobacterium longum BL999 and prebiotics. Nutrition 23, 1-8.
102. World Health Organization (2013) Cardiovascular disease fact sheet n. 317. http://www.who.int/mediacentre/ factsheets/fs317/en/index.html (accessed February 2013).

103. Grundy SM, Cleeman JI, Merz CN, et al. (2004) Implications of recent clinical trials for the National Cholesterol Education Program Adult Treatment Panel III guidelines. Circulation 110, 227-239.

104. Houston MC, Fazio S, Chilton FH, et al. (2009) Nonpharmacologic treatment of dyslipidemia. Prog Cardiovasc Dis 52, 61-94.

105. Mann GV \& Spoerry A (1974) Studies of a surfactant and cholesterolemia in the Maasai. Am J Clin Nutr 27, 464-469.

106. Ooi LG \& Liong MT (2010) Cholesterol-lowering effects of probiotics and prebiotics: a review of in vivo and in vitro findings. Int J Mol Sci 11, 2499-2522.

107. Zhuang G, Liu XM, Zhang QX, et al. (2012) Research advances with regards to clinical outcome and potential mechanisms of the cholesterol-lowering effects of probiotics. Clin Lipidol 7, 501-507.

108. Kumar M, Nagpal R, Kumar R, et al. (2012) Cholesterollowering probiotics as potential biotherapeutics for metabolic diseases. Exp Diabetes Res 2012, Article ID 902917.

109. Davis HR Jr, Zhu LJ, Hoos LM, et al. (2004) Niemann-Pick C1 Like 1 (NPC1L1) is the intestinal phytosterol and cholesterol transporter and a key modulator of whole-body cholesterol homeostasis. J Biol Chem 279, 33586-33592.

110. Jeun J, Kim S, Cho SY, et al. (2010) Hypocholesterolemic effects of Lactobacillus plantarum KCTC3928 by increased bile acid excretion in C57BL/6 mice. Nutrition 26, 321-330.

111. Park YH, Kim JG, Shin YW, et al. (2007) Effect of dietary inclusion of Lactobacillus acidophilus ATCC 43121 on cholesterol metabolism in rats. J Microbiol Biotechnol 17, 655-662.

112. Agerholm-Larsen L, Raben A, Haulrik N, et al. (2000) Effect of 8 week intake of probiotic milk products on risk factors for cardiovascular diseases. Eur J Clin Nutr 54, 288-297.

113. Naruszewicz M, Johansson ML, Zapolska-Downar D, et al. (2002) Effect of Lactobacillus plantarum 299v on cardiovascular disease risk factors in smokers. Am J Clin Nutr 76, 1249-1255.

114. Ataie-Jafari A, Larijani B, Majd HA, et al. (2009) Cholesterollowering effects of probiotic yogurt in comparison with ordinary yogurt in mildly to moderately hypercholesterolemic subjects. Ann Nutr Metab 54, 22-27.

115. Jones ML, Martoni CJ, Parent M, et al. (2012) Cholesterollowering efficacy of a microencapsulated bile salt hydrolase-active Lactobacillus reuteri NCIMB 30242 yoghurt formulation in hypercholesterolaemic adults. Br J Nutr $\mathbf{1 0 7}$, $1505-1513$

116. Bedani R, Rossi EA, Cavallini DCU, et al. (2015) Influence of daily consumption of synbiotic soy-based product supplemented with okara soybean by-product on risk factors for cardiovascular diseases. Food Res Int 73, 142-148.

117. de Roos NM, Schouten G \& Katan MB (1999) Yogurt enriched with Lactobacillus acidophilus does not lower blood lipids in healthy men and women with normal to borderline high serum cholesterol levels. Eur J Clin Nutr 53, 277-280.

118. Simons LA, Armansec SG \& Conway P (2006) Effect of Lactobacillus fermentum on serum lipids in subjects with elevated serum. Nutr Metab Cardiovasc Dis 16, 531-535.

119. Balcázar-Muñoz BR, Martínez-Abundis E \& Gonzáles-Ortiz M (2003) Effect of oral inulin administration on lipid profile and insulin sensitivity in subjects with obesity and dyslipidemia. Revista Médica de Chile 131, 597-604.

120. Nichenametla SN, Weidauer LA, Wey HE, et al. (2014) Resistant starch type 4-enriched diet lowered blood 
cholesterols and improved body composition in a double blind controlled cross-over intervention. Mol Nutr Food Res 58, 1365-1369.

121. Giacco R, Clemente G, Luongo D, et al. (2004) Effects of short-chain fructo-oligosaccharides on glucose and lipid metabolism in mild hypercholesterolaemic individuals. Clin Nutr 23, 331-340.

122. Kellow NJ, Coughlan MT \& Reid CM (2014) Metabolic benefits of dietary prebiotics in human subjects: a systematic review of randomised controlled trials. Br J Nutr 111, 1147-1161.

123. Rault-Nania MH, Gueux E, Demougeot C, et al. (2006) Inulin attenuates atherosclerosis in apolipoprotein E-deficient mice. Br J Nutr 96, 840-844.

124. Ranganna K, Yatsu FM, Hayes BE, et al. (2000) Butyrate inhibits proliferation-induced proliferating cell nuclear antigen expression (PCNA) in rat vascular smooth muscle cells. Mol Cell Biochem 205, 149-161.

125. Tang WH \& Hazen SL (2014) The contributory role of gut microbiota in cardiovascular disease. J Clin Invest 124, $4204-4211$.

126. Lavanda I, Saad SML, Lobo AR, et al. (2011) Prebióticos y su efecto en la biodisponibilidad del calcio (Prebiotics and their effect on calcium bioavailability). Revista de Nutrição 24, 333-344.

127. Pedreschi R, Campos D, Noratto G, et al. (2003) Andean yacon root (Smallanthus sonchifolius Poepp. Endl) fructooligosaccharides as a potential novel source of prebiotics. J Agric Food Chem 51, 5278-5284.

128. Raschka L \& Daniel H (2005) Mechanisms underlying the effects of inulin-type fructans on calcium absorption in the large intestine of rats. Bone 37, 728-735.

129. Kruger MC, Brown KE, Collett G, et al. (2003) The effect of fructooligosaccharides with various degrees of polymerization on calcium bioavailability in the growing rat. Exp Biol Med 228, 683-688.

130. Coxam V (2005) Inulin-type fructans and bone health: state of the art and perspectives in the management of osteoporosis. Br J Nutr 93, 111-123.

131. Lobo AR, Mancini-Filho J, Alvares EP, et al. (2009) Effects of dietary lipid composition and inulin-type fructans on mineral bioavailability in growing rats. Nutrition 25, 216-225.

132. Scholz-Ahrens KE, Ade P, Marten B, et al. (2007) Prebiotics, probiotics, and synbiotics affect mineral absorption, bone mineral content, and bone structure. J Nutr 137, 838-846.

133. van der Heuvel EG, Muijs T, Van Dokkum W, et al. (1999) Lactulose stimulates calcium absorption in postmenopausal women. J Bone Miner Res 14, 1211-1216.

134. van der Heuvel EG, Schoterman MH \& Muijs T (2000) Transgalactooligosaccharides stimulate calcium absorption in postmenopausal women. J Nutr 130, 2938-2942.

135. Coudray C, Bellanger J, Castiglia-Delavaud C, et al. (1997) Effect of soluble or partly soluble dietary fibres supplementation on absorption and balance of calcium, magnesium, iron and zinc in healthy young man. Eur J Clin Nutr 51, 375-380.

136. Tahiri M, Tressol JC, Arnaud J, et al. (2003) Effect of short-chain fructooligosaccharides on intestinal calcium absorption and calcium status in postmenopausal women: a stable-isotope study. Am J Clin Nutr 77, 449-457.

137. Noack J, Dongowski G, Hartmann L, et al. (2000) The human gut bacteria Bacteroides thetaiotaomicron and Fusobacterium varium produce putrescine and spermidine in cecum of pectin-fed gnotobiotic rats. J Nutr 130, 1225-1231.

138. Bongers A \& Van Den Heuvel EGHM (2003) Prebiotics and the bioavailability of minerals and trace elements. Food Rev Int 19, 397-422.
139. Scholz-Ahrens KE \& Schrezenmeir J (2007) Inulin and oligofructose and mineral metabolism: the evidence from animal trials. J Nutr 137, 2513-2523.

140. Reid G (2008) Probiotic lactobacilli for urogenital health in women. J Clin Gastroenterol 42, 234-236.

141. Gardiner GE, Heinemann C, Baroja ML, et al. (2002) Oral administration of the probiotic combination Lactobacillus rhamnosus GR-1 and L. fermentum RC-14 for human intestinal applications. Int Dairy J 12, 191-196.

142. Antonio MA, Hawes SE \& Hillier SL (1999) The identification of vaginal Lactobacillus species and the demographic and microbiologic characteristics of women colonized by these species. J Infect Dis 180, 1950-1956.

143. Martin HLB, Richardson BA, Nyange PM, et al. (1999) Vaginal lactobacilli, microbial flora, and risk of human immunodeficiency virus type 1 and sexually transmitted disease acquisition. J Infect Dis 180, 1863-1868.

144. Donders GGG, Bosmans E, Dekeersmaecker A, et al. (2000) Pathogenesis of abnormal vaginal flora. Am J Obstet Gynecol 182, 872-878.

145. McLean NW \& McGroarty JA (1996) Growth inhibition of metronidazole-susceptible and metronidazole-resistant strains of Gardnerella vaginalis by lactobacilli in vitro. Appl Environ Microbiol 62, 1089-1092.

146. Reid G (2001) Probiotic agents to protect the urogenital tract against infection. Am J Clin Nutr 73, 437-443.

147. Lepargneur JP \& Rousseau V (2002) Protective role of the Doderleïn flora. J Gynecol Obstet Biol Reprod 31, 485-494.

148. Valore EV, Park CH, Igreti SL, et al. (2002) Antimicrobial components of vaginal fluid. Am J Obstet Gynecol 187, 561-568.

149. Martin R, Soberon N, Vasquez F, et al. (2008) Vaginal microbiota: composition, protective role, associated pathologies, and therapeutic perspectives. Enferm Infecc Microbiol Clin 26, 160-167.

150. Reid G \& Burton J (2002) Use of Lactobacillus to prevent infection by pathogenic bacteria. Microbes Infect 4, 319-324.

151. Reid G \& Bocking A (2003) The potential for probiotics to prevent bacterial vaginosis and preterm labor. Am J Obstet Gynecol 189, 1202-1208.

152. Reid G \& Bruce AW (2003) Urogenital infections in women: can probiotics help? J Postgrad Med 79, 428-432.

153. Reid G, Charbonneau D, Erb J, et al. (2003) Oral use of Lactobacillus rhamnosus GR-1 and L. fermentum RC-14 significantly alters vaginal flora: randomized, placebocontrolled trial in 64 healthy women. FEMS Immunol Med Microbiol 35, 131-134.

154. Reid G (2012) Probiotic and prebiotic applications for vaginal health. $J A O A C$ Int $95,31-34$.

155. Bruce AW \& Reid G (1988) Intravaginal instillation of lactobacilli for prevention of recurrent urinary tract infections. Can J Microbiol 34, 339-343.

156. Bruce AW, Reid G, McGroarty JA, et al. (1992) Preliminary study on the prevention of recurrent urinary tract infections in ten adult women using intravaginal lactobacilli. Int Urogynecol J 3, 22-25.

157. Martinez RCR, Franceschini SA, Patta MC, et al. (2009) Improved treatment of vulvovaginal candidiasis with fluconazole plus probiotic Lactobacillus rhamnosus GR-1 and Lactobacillus reuteri RC-14. Lett Appl Microbiol 48, 269-274.

158. Anukam K, Osazuwa E, Ahonkhai I, et al. (2006) Augmentation of antimicrobial metronidazole therapy of bacterial vaginosis with oral probiotic Lactobacillus rhamnosus GR-1 and Lactobacillus reuteri RC-14: randomized, double-blind, placebo controlled trial. Microbes Infect 8, 1450-1454. 
159. Martinez RCR, Franceschini SA, Patta MC, et al. (2009) Improved cure of bacterial vaginosis with single dose of tinidazole (2g) and Lactobacillus rhamnosus GR-1 and Lactobacillus reuteri RC-14: a randomized, double-blind, placebo-controlled trial. Can J Microbiol 55, 133-138.

160. Williams AB, Yu C, Tashima K, et al. (2001) Evaluation of two self-care treatments for prevention of vaginal candidiasis in women with HIV. J Gen Microbiol 12, 51-57.

161. Pirotta M, Gunn J, Chondros P, et al. (2004) Effect of Lactobacillus in preventing post-antibiotic vulvovaginal candidiasis: a randomized controlled trial. BMJ 329, 548.

162. Larsson PG, Stray-Pedersen B, Ryttig KR, et al. (2008) Human lactobacilli as supplementation of clindamycin to patients with bacterial vaginosis reduce the recurrence rate; a 6-month, double-blind, randomized, placebocontrolled study. BMC Womens Health $\mathbf{8}, 3$.

163. Eriksson K, Carlsson B, Forsum U, et al. (2005) A doubleblind treatment study of bacterial vaginosis with normal vaginal lactobacilli after an open treatment with vaginal clindamycin ovules. Acta Derm Venereol 85, 42-46.

164. Bizzini B, Pizzo G, Scapagnini G, et al. (2012) Probiotics and oral health. Curr Pharma Des 18, 5522-5531.

165. Selwitz RH, Ismail AI \& Pitts NB (2007) Dental caries. Lancet 369, $51-59$.

166. Islam B, Khan S \& Khan A (2007) Dental caries: from infection to prevention. Med Sci Monit 13, 196-203.

167. Bonifait L, Chandad F \& Grenier D (2009) Probiotics for oral health: myth or reality? J Can Dent Assoc 75, 585-590.

168. Ahola AJ, Yli-Knnuuttila H, Suomalainen T, et al. (2002) Short-term consumption of probiotic-containing cheese and its effect on dental caries risk factors. Arch Oral Biol 47, 799-804.

169. Nikawa H, Makihira S, Fukushima H, et al. (2004) Lactobacillus reuteri in bovine milk fermented decreases the oral carriage of mutans streptococci. Int J Food Microbiol 95 , 219-223.

170. Kang MS, Chung J, Kim SM, et al. (2006) Effect of Weissella cibaria isolates on the formation of Streptococcus mutans biofilm. Caries Res 40, 418-425.

171. Houle MA \& Grenier D (2003) Maladies parodontales: connaissances actuelles (Current concepts in periodontal diseases). Méd Maladies Infect 33, 331-340.

172. Sookkhee S, Chulasiri M \& Prachyabrued W (2001) Lactic acid bacteria from healthy oral cavity of Thai volunteers: inhibition of oral pathogens. J Appl Microbiol 90, 172-179.

173. Koll-Klais P, Mandar R, Leibur E, et al. (2005) Oral lactobacilli in chronic periodontitis and periodontal health: species composition and antimicrobial activity. Oral Microbiol Immunol 20, 354-361.

174. Krasse P, Carisson B, Dahl C, et al. (2006) Decreased gum bleeding and reduced gingivitis by the probiotic Lactobacillus reuteri. Swed Dent J 30, 55-60.

175. Riccia DN, Bizzini F, Perilli MG, et al. (2007) Anti-inflammatory effects of Lactobacillus brevis (CD2) on periodontal disease. Oral Dis 13, 376-385.

176. Laleman I \& Teughels W (2015) Probiotics in the dental practice: a review. Quintessence Int 46, 255-264.

177. Scully C \& Greenman J (2008) Halitosis (breath odor). Periodontology 48, 66-75.

178. Burton JP, Chicott CN \& Tagg JR (2005) The rationale and potential for the reduction of oral malodour using Streptococcus salivarius probiotics. Oral Dis 11, 29-31.

179. Keller MK, Bardow A, Jensdottir T, et al. (2012) Effect of chewing gums containing the probiotic bacterium Lactobacillus reuteri on oral malodour. Acta Odontol Scand 70, 246-250.
180. Schabussova I \& Wiedermann U (2008) Lactic acid bacteria as novel adjuvant systems for prevention and treatment of atopic diseases. Curr Opin Allergy Clin Immunol 8, 557-564.

181. Penders J, Stobberingh EE, Van Den Brandt PA, et al. (2007) The role of the intestinal microbiota in the development of atopic disorders. Allergy 62, 1223-1236.

182. Prescott SL \& Bjorksten B (2007) Probiotics for the prevention or treatment of allergic diseases. J Allergy Clin Immunol 120, 255-262.

183. Bjorksten B, Sepp E, Julge K, et al. (2001) Allergy development and the intestinal microflora during the first year of life. J Allergy Clin Immunol 108, 516-520.

184. Kalliomaki M, Kirjavainen P, Eerola E, et al. (2001) Distinct patterns of neonatal gut microflora in infants in whom atopy was and was not dveloping. J Allergy Clin Immunol 107, 129-134.

185. Sepp E, Julge K, Mikelsaar M, et al. (2005) Intestinal microbiota and immunoglobulin E responses in 5-year-old Estonian children. Clin Exp Allergy 35, 1141-1146.

186. Kukkonen K, Savilahti E, Haahtela T, et al. (2007) Probiotics and prebiotic galactooligosaccharides in the prevention of allergic diseases: a randomized, double-blind, placebocontrolled trial. J Allergy Clin Immunol 119, 192-198.

187. Marschan E, Kuitunen M, Kukkonen K, et al. (2008) Probiotics in infancy induce protective immune profiles that are characteristic for chronic low-grade inflammation. Clin Exp Allergy 38, 611-618.

188. Rautava S, Kalliomaki M \& Isolauri E (2002) Probiotics during pregnancy and breast-feeding might confer immunomodulatory protection against topic disease in the infant. J Allergy Clin Immunol 109, 119-121.

189. Kopp MV, Hennemuth I, Heinzmann A, et al. (2008) Randomized, double-blind, placebo-controlled trial of probiotics for primary prevention: no clinical effects of Lactobacillus GG supplementation. Pediatrics 121, 850-856.

190. Kim SO, Ah YM, Yu YM, et al. (2014) Effects of probiotics for the treatment of atopic dermatitis: a meta-analysis of randomized controlled trials. Ann Allergy Asthma Immunol 113, 217-226.

191. Martinez-Canavate A, Sierra S, Lara-Villoslada F, et al. (2009) A probiotic dairy product containing L. gasseri CECT5714 and L. coryniformis CEC5711 induces immunological changes in children suffering from allergy. Pediatr Allergy Immunol 20, 592-600.

192. Majamaa H \& Isolauri E (1997) Probiotics: a novel approach in the management of food allergy. J Allergy Clin Immunol 99, 179-185.

193. Isolauri E, Rautava S, Kalliomaki M, et al. (2002) Role of probiotics in food hypersensitivity. Curr Opini Allergy Clin Immunol 2, 263-271.

194. Osborn DA \& Sinn JKH (2009) Probiotics in infants for prevention of allergic disease and food hypersensitivity. Cochrane Database of Systematic Reviews, issue 4, CD006475, http://onlinelibrary.wiley.com/doi/10.1002/ 14651858.CD006475.pub2/epdf.

195. Wells JM \& Mercenier A (2008) Mucosal delivery of therapeutic and prophylactic molecules using lactic acid bacteria. Nat Rev Microbiol 6, 349-362.

196. Sashihara T, Sueki N \& Ikegami S (2006) An analysis of the effectiveness of heat-killed lactic acid bacteria in alleviating allergic diseases. J Dairy Sci 89, 2846-2855.

197. Medina M, Izquierdo E, Ennahar S, et al. (2007) Differential immunomodulatory properties of Bifidobacterium longum strains: relevance to probiotic selection and clinical applications. Clin Exp Immunol 150, 531-538.

198. Kekkonen RA, Kajasto E, Miettinen M, et al. (2008) Probiotic Leuconostoc mesenteroides spp. cremoris and Streptococcus 
thermophilus induce IL-2 and IFN-gamma production. World J Gastroenterol 14, 1192-1203.

199. Foligne B, Zoumpopoulou G, Dewulf J, et al. (2007) A key role of dendritic cells in probiotic functionality. PLOS ONE 2, e313.

200. Blander JM \& Medzhitov R (2006) Toll-dependent selection of microbial antigens for presentation by dendritic cells. Nature 440, 808-812.

201. Fujiwara D, Inoue S, Wakabayashi H, et al. (2004) The antiallergic effects of lactic acid bacteria are strain dependent and mediated by effects on both Th1/Th2 cytokine expression and balance. Int Arch Allergy Immunol 135, 205-215.

202. Kalliomäki M, Antoine JM, Herz U, et al. (2010) Guidance for substantiating the evidence for beneficial effects of probiotics: prevention and management of allergic diseases by probiotics. J Nutr 140, 713-721.

203. Niele N, van Zwol A, Westerbeek EAM, et al. (2013) Effect of non-human neutral and acidic oligosaccharides on allergic and infectious diseases in preterm infants. EurJ Pediatr 172, 317-323.

204. Schouten B, Van Esch BC, Kormelink TG, et al. (2011) Non-digestible oligosaccharides reduce immunoglobulin free light-chain concentrations in infants at risk for allergy. Pediatr Allergy Immunol 22, 537-542.

205. Williams HC \& Grindlay DJ (2010) What's new in atopic eczema? An analysis of systematic reviews published in 2007 and 2008. Part 1: definitions, causes and consequences of eczema. Clin Exp Dermatol 35, 12-15.

206. Osborn DA \& Sinn JKH (2013) Prebiotics in infants for prevention of allergy. Cochrane Database of Systematic Reviews, issue 28, CD006474. http://onlinelibrary.wiley.com/doi/ 10.1002/14651858.CD006474.pub3/epdf.

207. Jonkers D, Penders J, Masclee A, et al. (2012) Probiotics in the management of inflammatory bowel disease. Drugs $\mathbf{7 2}$, 803-823.

208. Kawada M, Arihiro A \& Mizoguchi E (2007) Insights from advances in research of chemically induced experimental models of human inflammatory bowel disease. World $J$ Gastroenterol 13, 5581-5593.

209. Abraham C \& Medzhitov R (2011) Interaction between the host innate immune system and microbes in inflammatory bowel disease. Gastroenterology 140, 1729-1737.

210. Danese S (2011) Immune and nonimmune components orchestrate the pathogenesis of inflammatory bowel disease. Am J Physiol Gastrointest Liver Physiol 300, 716-722.

211. Dignass A, Van Assche G, Lindsay JO, et al. (2010) The second European evidence-based consensus on the diagnosis and management of Crohn's disease: current management. J Crohn's Colitis 4, 28-62.

212. Lebeer S, Vanderleyden J \& De Keersmaecker SC (2008) Genes and molecules of lactobacilli supporting probiotic action. Microbiol Mol Biol Rev 72, 728-764.

213. Oelschlaeger TA (2010) Mechanisms of probiotics actions a review. Int J Med Microbiol 300, 57-62.

214. Borchers AT, Selmi V, Meyers FJ, et al. (2009) Probiotics and immunity. J Gastroenterol 44, p. 26-46.

215. Caballero-Franco C, Keller K, De Simone C, et al. (2007) The VSL\#3 probiotic formula induces mucin gene expression and secretion in colonic epithelial cells. Am J Physiol Gastrointest Liver Physiol 291, 315-322.

216. Karczewski J, Troost FJ, Konings I, et al. (2010) Regulation of human epithelial tight junction proteins by Lactobacillus plantarum in vivo and protective effects on the epithelial barrier. Am J Physiol Gastrointest Liver Physiol 298, $851-859$.

217. Ng SC, Plamondon S, Kamm MA, et al. (2010) Immunosuppressive effects via human intestinal dendritic cells of probiotic bacteria and steroids in the treatment of acute ulcerative colitis. Inflamm Bowel Dis 16, 1286-1298.

218. Rahimi R, Nikfar S, Rahimi F, et al. (2008) A meta-analysis on the efficacy of probiotics for maintenance of remission and prevention of clinical and endoscopic relapse in Crohn's disease. Dig Dis Sci 53, 2524-2531.

219. Shen J, Zuo ZX \& Mao AP (2014) Effect of probiotics on inducing remission and maintaining therapy in ulcerative colitis, Crohn's disease, and pouchitis: meta-analysis of randomized controlled trials. Inflamm Bowel Dis 20, 21-35.

220. Rijkers GT, Bengmark S, Enck P, et al. (2010) Guidance for substantiating the evidence for beneficial effects of probiotics: current status and recommendations for future research. J Nutr 140, 671-676.

221. Moayyedi P, Ford AC, Talley NJ, et al. (2010) The efficacy of probiotics in the treatment of irritable bowel syndrome: a systematic review. Gut 59, 325-332.

222. Spiller R, Aziz Q, Creed F, et al. (2007) Guidelines on the irritable bowel syndrome: mechanisms and practical management. Gut 56, 1770-1798.

223. Clarke G, Cryan JF, Dinan TG, et al. (2012) Review article: probiotics for the treatment of irritable bowel syndrome focus on lactic acid bacteria. Aliment Pharmcol Ther 35 , 403-413.

224. Brenner DM, Moeller MJ, Chey WD, et al. (2009) The utility of probiotics in the treatment of irritable bowel syndrome: a systematic review. Am J Gastroenterol 104, 1033-1049.

225. Parkes GC, Sanderson JD \& Whelan K (2010) Treating irritable bowel syndrome with probiotics: the evidence. Proc Nutr Soc 69, 187-194.

226. Horvath A, Dziechciarz P \& Szajewska H (2011) Metaanalysis: Lactobacillus rhamnosus GG for abdominal pain-related functional gastrointestinal disorders in childhood. Aliment Pharmcol Ther 33, 1302-1310.

227. Ringel Y \& Ringel-Kulka T (2011) The rationale and clinical effectiveness of probiotics in irritable bowel syndrome. J Clin Gastroenterol 45, 145-148.

228. Whelan K (2014) The importance of systematic reviews and meta-analyses of probiotics and prebiotics. Am J Gastroenterol 109, 1563-1565.

229. Haller D, Antoine JM, Bengmark S, et al. (2010) Guidance for substantiating the evidence for beneficial effects of probiotics: probiotics in chronic inflammatory bowel disease and the functional disorder irritable bowel syndrome. J Nutr 140, 690-697.

230. O'Mahony L, Mccarthy J, Kelly P, et al. (2005) Lactobacillus and Bifidobacterium in irritable bowel syndrome: symptom responses and relationship to cytokine profiles. Gastroenterology 128, 541-551.

231. Whorwell PJ, Altringer L, Morel J, et al. (2006) Efficacy of an encapsulated probiotic Bifidobacterium infantis 35624 in women with irritable bowel syndrome. Am J Gastroenterol 101, 1581-1590.

232. Bonfrate L, Tack J, Grattagliano I, et al. (2013) Microbiota in health and irritable bowel syndrome: current knowledge, perspectives and therapeutic options. Scand J Gastroenterol 48, 995-1009.

233. Hunter JO, Tuffnell Q \& Lee AJ (1999) Controlled trial of oligofructose in the management of irritable bowel syndrome. J Nutr 129, 1451-1453.

234. Olesen M \& Gudmand-Hoyer E (2000) Efficacy, safety, and tolerability of fructooligosaccharides in the treatment of irritable bowel syndrome. Am J Clin Nutr 72, 1570-1575.

235. Silk DBA, Davis A, Vulevic J, et al. (2009) Clinical trial: the effects of a trans-galactooligosaccharide prebiotic on faecal microbiota and symptoms in irritable bowel syndrome. Aliment Pharmcol Ther 29, 508-518. 
236. Andriulli A, Neri M, Loguercio C, et al. (2008) Clinical trial on the efficacy of a new symbiotic formulation, Flortec, in patients with irritable bowel syndrome: a multicenter, randomized study. J Clin Gastroenterol 42, 218-223.

237. Guandalini S, Cernat E \& Moscoso D (2015) Prebiotics and probiotics in irritable bowel syndrome and inflammatory bowel disease in children. Benef Microbes 6, 209-217.

238. Floch MH (2014) Recommendations for probiotic use in humans - a 2014 update. Pharmaceuticals 7, 999-1007.

239. Lesbros-Pantoflickova D, Corthesy-Theulaz I \& Blum AL (2007) Helicobacter pylori and probiotics. J Nutr 137, 812-818.

240. Michetti P, Dorta G, Wiesel PH, et al. (1999) Effect of wheybased culture supernatant of Lactobacillus acidophilus (johnsonii) La1 on Helicobacter pylori infection in humans. Digestion 60, 203-209.

241. Ruggiero P (2014) Use of probiotics in the fight against Helicobacter pylori. World J Gastrointest Pathophysiol 5, 384-391.

242. Felley CP, Corthesy-Theulaz I, Rivero JL, et al. (2001) Favourable effect of an acidified milk (LC-1) on Helicobacter pylori gastritis in man. Eur J Gastroenterol Hepatol 13, 25-29.

243. Pantoflickova D, Corthesy-Theulaz I, Dorta G, et al. (2003) Favorable effect of long-term intake of fermented milk containing Lactobacillus jobnsonii on $\mathrm{H}$. pylori associated gastritis. Aliment Pharmacol Ther 18, 805-813.

244. Wang KY, Li SN, Liu CS, et al. (2004) Effects of ingesting Lactobacillus- and Bifidobacterium-containing yogurt in subjects with colonized Helicobacter pylori. Am J Clin Nutr 80, 737-741.

245. Lionetti E, Miniello VL, Castellaneta SP, et al. (2006) Lactobacillus reuteri therapy to reduce side-effects during anti-Helicobacter pylori treatment in children: a randomized placebo controlled trial. Aliment Pharmacol Ther 24, 1461-1468.

246. Francavilla R, Polimeno L, Demichina A, et al. (2014) Lactobacillus reuteri strain combination in Helicobacter pylori infection - a randomized, double-blind, placebocontrolled study. J Clin Gastroenterol 48, 407-413.

247. Yang YJ, Chuang CC, Yang HB, et al. (2012) Lactobacillus acidophilus ameliorates $H$. pylori induced gastric inflammation by inactivating the Smad7 and NFKB pathways. BMC Microbiol 12, 38.

248. Chen X, Liu XM, Tian F, et al. (2012) Antagonistic activities of lactobacilli against Helicobacter pylori growth and infection in human gastric epithelial cells. J Food Sci 77, 9-14.

249. Navarro-Rodriguez T, Silva FM, Barbuti RC, et al. (2013) Association of a probiotic to a Helicobacter pylori eradication regimen does not increase efficacy or decreases the adverse effects of the treatment: a randomized, double-blind, placebo-controlled study. BMC Gastroenterol 13, 56.

250. Szajewska H, Horvath A \& Piwowarczyk A (2010) Meta-analysis: the effects of Saccharomyces boulardii supplementation on Helicobacter pylori eradication rates and side effects during treatment. Aliment Pharmacol Ther 32, 1069-1079.

251. Zhang MM, Qian W, Qin YY, et al. (2015) Probiotics in Helicobacter pylori eradication therapy: a systematic review and meta-analysis. World $J$ Gastroenterol 21, $4345-4357$.

252. Katan MB (2012) Why the European Food Safety Authority was right to reject health claims on probiotics. Benef Microbes 3, 85-89.

253. Glanville J, King S, Guarner F, et al. (2015) A review of the systematic review process and its applicability for use in evaluating evidence for health claims on probiotic foods in the European Union. J Nutr 14, 16.

254. Bisanz JE, Enos MK, Mwanga JR, et al. (2014) Randomized open-label pilot study of the influence of probiotics and the gut microbiome on toxic metal levels in Tanzanian pregnant women and school children. MBio 5, e01580-14. 